\title{
A moderated target design for minor actinide transmutation in sodium-cooled fast reactor
}

\author{
Tongkyu Park ${ }^{1}$, Ching-Sheng Lin, and Won Sik Yang*
}

School of Nuclear Engineering, Purdue University, 400 Central Dr., West Lafayette, IN 47907, USA

${ }^{1}$ Permanent Address: FNC Technology, Heungdeok IT Valley Bldg. 32F, 13, Heungdeok 1-ro, Giheung-gu, Yongin-Si, Gyeonggi-do, 446-908, Korea

*Corresponding Author

Prof. Won Sik Yang

School of Nuclear Engineering, Purdue University

400 Central Dr., West Lafayette, IN 47907, USA

Phone: +1-765-494-4710

Fax: +1-765-494-5739

E-mail address: yang494@purdue.edu

Number of Pages

Text: 30 (including the cover page and the list of table and figure captions)

Tables: 6

Figures: 13 


\begin{abstract}
This paper presents a moderated target assembly design study for minor actinide (MA) transmutation in the first-stage sodium-cooled fast reactor (FR) to reduce the amount of MA to be sent to the second-stage accelerator driven system (ADS) in a two-stage FR/ADS fuel cycle option. In order to minimize the local power peaking problem induced by moderated target assemblies, the target assemblies were loaded in the reflector region. Using MA-40Zr target composition and $\mathrm{ZrH}_{1.6}$ moderator, an optimum MA target assembly design was developed to maximize the MA destruction within the practical thermal design limits on the cladding inner wall temperature. Long-lived fission product pins were used as thermal neutron filters to reduce the local power peaking in the adjacent fuel assemblies due to the thermal neutron leakage from the moderated target assembly. The performance characteristics of the FR with moderated target assemblies were evaluated by performing detailed neutronics and thermal-hydraulics analyses. Analysis results showed that the use of MA target assemblies reduces the amount of MA to be sent to ADS by a factor of six without deteriorating safety characteristics. As a result, the electricity sharing of ADS in a nuclear park composed of FRs and ADSs was reduced to 0.3\% from $1.9 \%$.
\end{abstract}

Keywords: Moderated Minor Actinide Target, Two-stage Fuel Cycle Option, Sodiumcooled Fast Reactor, Accelerator Driven System 


\section{Introduction}

The Office of Fuel Cycle Technologies of the Department of Energy’s Office of Nuclear Energy conducted an Evaluation and Screening (E\&S) study to identify potentially promising fuel cycle options aiming at providing substantial improvements as compared to the current fuel cycle in United States, including both benefits and challenges for development (Wigeland et al., 2014). In the E\&S study, a comprehensive set of fuel cycle options were represented by an associated set of fuel cycle evaluation groups (EGs), and promising EGs were identified with simultaneous consideration of key fuel cycle characteristics such as continuous recycle of actinide elements, fast neutron spectrum reactors, critical reactors, high internal conversion, and no uranium enrichment required once steady-state conditions are established. However, only a representative fuel cycle option was identified and analyzed for each EG in the E\&S study, and hence the remaining fuel cycle options are still to be analyzed.

In order to provide supporting information for the E\&S study, a two-stage, fast-spectrum fuel cycle option has recently been proposed aiming at enhancing the natural resource utilization and reducing the nuclear waste to be sent to the geological repository (Lin et al., 2016a, 2016b). The first-stage is a sodium-cooled fast reactor (FR) fuel cycle and the second-stage is a sodiumcooled accelerator driven system (ADS) cycle. Design studies were performed for the FR core (Lin et al., 2015, 2016a, 2016b) and the ADS blanket (Lin et al., 2016a, 2016b). The first-stage FR starts with low-enriched uranium (LEU) fuels, but it can be operated without supporting LEU fuels at equilibrium cycle. U-10Zr and U-Pu-10Zr metal alloy fuels are used as the startup and recycled fuels, respectively. A heterogeneous recycling strategy in which minor actinides (MA) are separated from the driver fuels was adopted because the addition of MA into driver fuels would make fuel handing more difficult due to the intense radiation emissions and heat (NEA, 
2012). Plutonium and uranium are co-extracted from the discharged fuels of FR and recycled back into the FR. On the other hand, the recovered MA is sent to the second-stage ADS blanket directly. The second-stage ADS burns the MA recovered from the first-stage FRs in an inert matrix fuel form. The discharged fuels of ADS are reprocessed, and all the recovered heavy metal (HM) is recycled back into the ADS along with the MA from the first-stage FR. All fission products from discharged fuels and the separation and fabrication losses of HMs are sent to the geological repository. Fuel cycle analysis results showed that the proposed two-stage fast spectrum fuel cycle option could increase the efficiency of natural resource utilization and reduce the nuclear waste to be sent to the geological repository, compared to the conventional two-stage fuel cycle options based on thermal and fast spectrum systems (Lin et al., 2016a, 2016b).

According to the E\&S study (Wigeland et al., 2014), the use of critical reactors lowers overall costs as compared to ADS. In addition, a high risk in operation of ADS needs to be considered when ADS is employed. Therefore, it is highly desirable to minimize the required number of ADSs in the proposed two-stage fuel cycle option. The number of ADSs in the second-stage can be minimized by reducing the amount of MA sent to the second-stage ADS through partial incineration of MA in the first-stage FR. The major MA nuclides in the discharged fuels of FR are Np-237 and Am-241 (Lin et al., 2016a, 2016b), which have relatively small fission-to-absorption cross section ratios in the fast energy range and large thermal capture cross sections (Waltar et al., 2012). These properties of MA suggest that a promising option for incinerating MA in the first-stage FR is to convert Np-237 and Am-241 first into fissile nuclides by neutron capture reactions in moderated target assemblies (NEA, 2012) and then burn the resulting fissile nuclides by fission reactions. 
The purpose of this work is to develop an optimum design for the moderated MA target assembly to be used in the first-stage FR and to assess the performance of the proposed twostage FR/ADS fuel cycle option with the MA target assemblies in the first-stage FR. The design goal of the MA target assembly is to maximize the MA destruction while staying within the imposed thermal design constraints. A significant concern with the utilization of moderator materials in FR is the possibility for localized power peaking either inside the target or in adjacent fuel assemblies (NEA, 2012). Therefore, the optimum moderator fraction in the target assembly needs to be determined in such a way that the MA transmutation performance is maximized while satisfying the peak linear power limits derived from the constraints on the fuel and cladding temperatures. To mitigate the local power peaking problem, the target assemblies can be loaded in the core periphery and long-lived fission product (LLFP) target pins can be used as the thermal neutron filter to reduce the thermal neutron leakage from a target assembly to the neighboring fuel assemblies (Yang, et al., 2004). In addition, the impacts of the moderated target assemblies on the safety parameters such as sodium void worth and Doppler coefficient need to be assessed.

This paper presents the developed MA target design and the associated performance of the proposed two-stage fast-spectrum fuel cycle option. This paper is organized as follows. Section 2 presents the optimum MA target design along with the design approaches and constraints. Section 3 discusses the core performance parameters of the first-stage FR with the moderated MA targets. Section 4 describes the fuel cycle performance of the two-stage FR/ADS fuel cycle option with the moderated targets in the first-stage FR. Finally, conclusions are summarized in Section 5. 


\section{Moderated Minor Actinide Target Design}

Fig. 1 shows the radial core layout of the 1000 MWt sodium-cooled fast reactor concept developed for the proposed two-stage fuel cycle option (Lin et al., 2015, 2016a, 2016b). The core consists of 186 drivers, 114 reflectors, 66 radial shields, 9 primary control and 4 secondary control assemblies. The cycle length is 18 months with an assumed capacity factor of $90 \%$. It was decided to load MA target assemblies in the reflector region in order to minimize the local power peaking problem induced by moderated target assemblies. An optimum design for the moderated MA target assembly was developed aiming at maximizing the MA transmutation performance while satisfying all the imposed thermal design constraints. The optimal fuel to moderator ratio in the target assembly was determined through parametric studies following the selection of moderating material and MA target composition. This section discusses the selection of moderator and fuel materials, the computational methods and design constraints, and the resulting moderated target design obtained from parametric studies.

\subsection{Selection of Moderator and Target Materials}

To transmute the Np-237 and Am-241 nuclides effectively, a proper moderating material and MA target composition must be selected. The two most important criteria for the moderating material are a high slowing-down power, which makes the number of collisions required to thermalize neutrons small, and a high slowing-down ratio, which yields a high thermal neutron flux. In considering the MA fuel composition, the important parameters to consider include the thermal conductivity, melting temperature, material density, fabrication cost, and compatibility with materials in the surrounding environment (sodium coolant). 
After examining several moderating materials including graphite, zirconium-hydride, zirconium-deutride, yttrium hydride, and cerium hydride, zirconium-hydride was selected as the moderator of the MA target based on its high moderating capability and extensive irradiation experience in TRIGA reactors (IAEA, 2011). Furthermore, zirconium-hydride has relatively high thermal conductivity and decomposition temperature. The stoichiometry for zirconium hydride of 1.6 (i.e., $\mathrm{ZrH}_{1.6}$ ) was selected because it is stable up to a temperature of at least $1000{ }^{\circ} \mathrm{C}$ (Moore and Young, 1968).

To take the advantage of the demonstrated performance of metal fuels, the MAcontaining metal alloy fuel was selected as the MA target material. The MA fuel composition was chosen to be MA-40Zr under the assumption that it would have similar properties as the Pu40Zr and Pu-MA-40Zr fuels. Metal fuel samples of Pu-40Zr, Pu-12Am-40Zr and Pu-10Am10Np-40Zr were irradiated in the Advanced Test Reactor and included in the Advanced Fuel Cycle irradiation test series to evaluate the effects caused by the existence of MAs (Carmack and Pasamehmetoglu, 2008; IAEA, 2010). Recent experimental results showed that the major irradiation performance variables of the metal fuel samples are similar to those of $\mathrm{U}-\mathrm{Zr}$ and $\mathrm{U}$ Pu-Zr fuels (Carmack and Pasamehmetoglu, 2008; IAEA, 2010), which are the startup and recycled fuel types of the first-stage FR of the two-stage fuel cycle option, respectively.

For the target assembly configuration, a heterogeneous lattice of MA-40Zr target pins and $\mathrm{ZrH}_{1.6}$ moderator pins was selected instead of mixing the target and moderator materials. Separate target and moderator pins would make easier fabrication and reprocessing and allow a higher linear power. The thermal neutron leakage from the target assembly to the neighboring fuel assemblies is reduced by replacing some MA target pins with thermal neutron filter pins. In 
order to reduce the amount of LLFP to be sent to the repository, LLFP is used as the thermal neutron filter.

\subsection{Design Constraints}

The increased moderation in the MA target assembly results in an increased power peaking in the adjacent fuel assemblies and the moderated target assemblies themselves when a significant amount of MAs is converted into fissile nuclides. As a result, the moderator volume fraction in the target assembly is limited by the peak linear power limit on the adjacent fuel assemblies (drivers) and the moderated MA target assemblies. Since the linear power in the target assembly is proportional to the irradiation time (i.e., the core residence time of a target assembly), the target irradiation time is also constrained.

Two thermal design constrains were imposed on the U-10Zr and U-Pu-10Zr driver fuels. The first constraint is that the centerline temperature of the hottest fuel pin should be less than the bulk melting temperature. The second constraint is that the cladding inner wall temperature should be less than the minimum value for macroscopic eutectic liquefaction at the fuel-cladding interface. Based on a series of out-of-pile experiments, the threshold temperature for high burnup U-Pu-10Zr fuel with HT-9 cladding was determined to be between $650^{\circ} \mathrm{C}$ and $660^{\circ} \mathrm{C}$ (Tsai, 1990). It was also shown that the threshold temperature is much higher at lower burnups. Although the eutectic melting temperature of the initial U-10Zr fuel is significantly higher than that of U-Pu-10Zr fuel, the minimum value of $650^{\circ} \mathrm{C}$ was used in this study to accommodate the recycled U-Pu-10Zr fuel. In addition, a fast fluence limit for HT-9 cladding was assumed about $4 \times 10^{23} \mathrm{n} / \mathrm{cm}^{2}$, based on the irradiation data of HT-9 obtained in Fast Flux Test Facility that

showed no duct elongation or cladding breach after a fast fluence of $3.9 \times 10^{23} \mathrm{n} / \mathrm{cm}^{2}$ (Leggett and Walters, 1993). 
For initial design iterations, a design constraint on the peak linear power was used instead of performing detailed thermal-hydraulics calculations. A limit on the local power peaking due to the moderator in target assemblies was also derived to superimpose on the peak linear power deduced from the whole core neutronics calculations with homogenized assembly modes. Based on single channel thermal-hydraulics analyses, it was found that the linear power limit from the constraint on the cladding inner wall temperature is lower than that from the constraint on the fuel centerline temperature. Therefore, the thermal constraint on the cladding inner wall temperature was selected as the design constraint. This constraint was imposed to limit the peak linear power in the hottest fuel pin so that macroscopic eutectic liquefaction at the fuel-cladding interface cannot occur. For the driver fuel assembly, the threshold temperature for the liquefaction point was estimated to be approximately $685{ }^{\circ} \mathrm{C}$ based on a series of out-of-pile experiments (Inagaki et al., 2013). This temperature was determined with 14 wt.\% Pu in U-Pu10Zr fuel since the maximum estimated Pu fraction in the FR core was about 13.3 wt.\% at the end of life (EOL) core (Lin et al, 2016a, 2016b). By applying a $15^{\circ} \mathrm{C}$ margin and 2-sigma hot channel factor uncertainties to the design limit, a maximum peak linear power of $54.8 \mathrm{~kW} / \mathrm{m}$ was obtained. Based on this design limit and the peak linear power in neighboring fuel assemblies calculated with non-equilibrium cycle-by-cycle analyses with homogenized assembly models, a maximum allowable local power peaking factor in neighboring fuel assemblies was determined to be 1.40 .

For the moderated target assembly, the liquefaction temperature would change with the isotopic compositions of MA fuel. However, almost no experimental information is available on the system containing $\mathrm{Np}, \mathrm{Am}, \mathrm{Pu}, \mathrm{Zr}$ and Fe. Therefore, the phase diagram for the Np-Fe system proposed by J. K. Gibson (Gibson et al, 1994) was used for determining the eutectic 
temperature of MA target fuels with HT-9 cladding since Np is the major nuclide in target pins. The eutectic temperature for the Np-Fe system is between the corresponding temperatures for the U-Fe and Pu-Fe systems. Compared to the U-Pu-10Zr fuel, the increased $\mathrm{Zr}$ weight fraction in the target composition can compensate for the deteriorated thermal properties due to the presence of MA. Consequently, for the MA-40Zr target assembly, a threshold temperature of $620^{\circ} \mathrm{C}$ was selected for the liquefaction point. The peak linear power limit of the target assembly was determined to be about $44 \mathrm{~kW} / \mathrm{m}$ based on single channel thermal-hydraulics analyses as well.

\subsection{Computational Methods}

The Argonne National Laboratory suite of fast reactor analysis codes was used for analyzing the FR with and without moderated targets. Using the DIF3D/REBUS-3 code system (Derstine, 1984; Lawrence, 1983; Toppel, 1983), equilibrium and non-equilibrium fuel cycle analyses were performed with 3-dimensional hexagonal-z geometry full core models. For each composition in the FR core except for the moderated target assembly, region-dependent, 33group neutron cross section sets were generated using the $\mathrm{MC}^{2}-3$ code (Lee and Yang, 2011) and the ENDF/B-VII.0 cross section library.

Since the $\mathrm{MC}^{2}-3$ code does not have a thermal spectrum calculation capability, the cross sections of the moderated MA target assemblies were generated by combining MCNP6 (LANL, 2014) and $M C^{2}-3$ calculations. For the $\mathrm{MC}^{2}-3$ calculation, a one-dimensional model consisting of a homogeneous target assembly located between the outer core and reflector regions was used. A whole core model of MCNP6 was developed to generate target assembly cross sections, where heterogeneous assembly models were used for the target and three adjacent fuel assemblies while homogeneous assembly models were used for the other assemblies. It was observed that the cross sections from MCNP6 agree well with those in $\mathrm{MC}^{2}-3$ except for the thermal group (E < 
$0.414 \mathrm{eV})$. To correct the additional small deviations in epithermal region, the cross section obtained from $\mathrm{MC}^{2}-3$ were replaced with MCNP6 cross sections for the last 12 groups from 22 to 33 .

MCNP6 whole-core models were also used to determine the increase in the local power peaking in adjacent fuel assemblies. The composition used in the MCNP6 whole-core models was extracted from REBUS-3 results. Based on the above observation that the peak linear power in the neighboring fuel assemblies is the largest at the cycle 16, homogenized fuel compositions were obtained by taking the average of the compositions at the beginning and the end of the cycle 16. The pin power increase in a heterogeneous assembly configuration due to the local distribution of the thermal flux leaking from the moderated target assembly was estimated using two whole-core MCNP6 models: one with no target assembly and the other with moderated target assembly. The local power peaking increase in a neighboring fuel assembly due to the moderated target assembly is determined by the ratio of the assembly power peaking factor with the MA target assembly to the averaged pin power of the same assembly in the base case with no MA target assembly.

\subsection{Parametric Studies for the Target Assembly}

Using the selected MA-40Zr fuel and $\mathrm{ZrH}_{1.6}$ moderator, parametric studies were performed to determine the optimal fuel to moderator ratio in the target assembly. The MA target to moderator ratio was varied by adjusting the numbers of target and moderator pins. Four different pin designs of diameters from $5.99 \mathrm{~mm}$ to $9.5 \mathrm{~mm}$ were used with fixed assembly

dimensions. Fig. 2 shows the effective one-group capture cross section of MA (i.e., the transmutation rate per unit MA nuclide and flux) as a function of the moderator to MA target volume ratio for four different target pin designs. The effective one-group capture cross section 
of MA increases monotonically with increasing moderator to MA target volume ratio. The target pin size affects the one-group cross section through the change in the spatial self-shielding effect, but this effect is relatively small and becomes noticeable only when the moderator to MA target volume ratio is larger than 3.0. Since the gain of small pin size through the reduced self-shielding effect is small, a relatively larger pin size of $9.5 \mathrm{~mm}$ diameter was selected to increase the MA loading per pin, which would increase the absolute transmutation rate. Under the same assembly dimensions with the driver assembly, this yields a target assembly of 169 pins.

Fig. 3 shows the normalized capture reaction rate and the normalized one-group capture cross section of the target assembly with target and moderator pins of $9.5 \mathrm{~mm}$ diameter as a function of the moderator to MA target volume ratio. The capture rate and one-group capture cross section were normalized to the corresponding values of the target assembly with no moderator pin. It can be observed from the one-group capture cross section that the relative transmutation rate increases with increasing moderator volume fraction. On the other hand, the increased moderator volume fraction results in a reduced MA loading and hence a reduced absolute transmutation rate. It is noted that the effectiveness of moderator decreases when the moderator to MA target volume ratio is larger than 2.0. These results suggest that a trade-off between the relative and absolute transmutation rates needs to be made depending on the imposed design constraints. Since the MA production rate is relatively low in the first-stage FR core starting from U-10Zr fuels, there exist more than sufficient spaces for target assemblies in the core that can accommodate the MA production in the first-stage FR. As a result, a higher MA burnup, which is favorable to reducing the reprocessing loss of MA, can be achieved by loading multiple target assemblies with a smaller amount of MA. Therefore, the moderator volume in the target assembly was maximized within the peak linear power limit of target pins. 
As noted above, the moderator volume fraction in the target assembly is limited by the peak linear power limit on the driver and target assemblies. Since the linear power in the target assembly is proportional to the irradiation time, i.e., the core residence time of a target assembly, the target irradiation time is also constrained. Fig. 4 shows the peak linear power in the target assembly after one cycle irradiation as a function of the moderator volume fraction in the target assembly. Using the peak linear power limit of $44 \mathrm{~kW} / \mathrm{m}$ mentioned in Section 2.2, the upper limit of the moderator volume fraction that allows at least one cycle irradiation is around $40 \%$. For the target assembly design with a smaller moderator volume fraction, the number of irradiation cycles can be increased so that the peak linear power at the end of irradiation approaches to the design limit. However, the transmutation rate per cycle increases with moderator volume fraction in the target assembly. To maximize the overall transmutation performance, a target assembly design with a moderator volume fraction of $39.2 \%$ was selected in this study, which satisfies the design limit imposed on the peak linear power in the target assembly.

Fig. 5 shows the reference configuration of target assembly. The target assembly contains 169 pins of $9.5 \mathrm{~mm}$ diameter and has the same assembly dimensions as the driver fuel assembly of the first-stage FR (Lin et al., 2015, 2016a, 2016b). Twenty-four MA target pins, one hundred and twenty-seven moderator pins, nine technetium (Tc) pins and nine calcium iodide $\left(\mathrm{CaI}_{2}\right)$ pins are almost evenly distributed in the target assembly. The red, blue, orange and yellow pins represent the $\mathrm{MA}, \mathrm{ZrH}_{1.6}$, Tc and $\mathrm{CaI}_{2}$ pins, respectively. The number of LLFP pins was determined based on the available amount of recovered LLFP from discharged fuels of the firststage FR and the loading management scheme of MA target assemblies. As can be seen in Fig. 5, 
some of the MAs pins and two types of thermal neutron filter pins are placed at the driver and target assembly interface to reduce the leakage of moderated neutrons to the fuel assemblies.

As mentioned in Section 2.3, the increase in the local power peaking in adjacent fuel assemblies was estimated using two whole-core MCNP6 models shown in Fig. 6: one with no target assembly (Fig. 6a) and the other with moderated target assembly (Fig. 6b). The composition used in the MCNP6 whole-core models was extracted from the REBUS-3 output of the FR. The local power peaking factor in the adjacent fuel assemblies obtained from these MCNP6 whole-core calculations was 1.36. This local power peaking factor satisfies its limiting value 1.4, estimated in Section 2.2 based on the fuel/cladding eutectic temperature.

\section{Performance Characteristics of the Moderated Target Design}

Using the target assembly design discussed in Section 2, the transmutation capability of the FR with moderated MA target assemblies was investigated. In order to minimize the local power peaking problem induced by moderated target assemblies, the target assemblies were loaded in the reflector region. The loading of target assemblies in the reflector region utilizes the neutrons leaking out of the core and minimizes the perturbation in the core performances. The safety characteristics and thermal design margins were also evaluated. Kinetics parameters, reactivity coefficients, and shutdown margins were also evaluated, focused on the impacts of the moderated target assemblies. Individual pin temperature distributions were calculated by performing steady-state whole-core sub-channel analyses.

\subsection{Computational Methods}

To evaluate the MA transmutation efficiency in the moderated target assemblies loaded in the first-stage FR, full-core depletion calculations were performed using the DIF3D/REBUS-3 
system. The performance of the target assembly at the equilibrium state was assessed by an equilibrium cycle analysis. The overall MA transmutation performance for an assumed plant lifetime of 60 years was also evaluated by an explicit cycle-by-cycle non-equilibrium cycle analysis.

Kinetics parameters and reactivity coefficients were estimated using the VARI3D (Smith et al., 2013) perturbation theory code, the DIF3D diffusion theory code, and the VARIANT (Palmiotti et al., 1995) transport theory code. The kinetics parameters and reactivity coefficients were calculated for the equilibrium cycle and compared with the counterparts of the FR with no MA target (Lin et al., 2016a, 2016b). The control requirements and shutdown margins were also estimated for the primary and secondary control systems.

Pin temperature distributions were calculated by detailed steady-state thermal-hydraulic analyses. Heating rates for thermal-hydraulic calculations were determined by coupled neutron and gamma heating calculations. For these heating calculations, region-dependent 33-group neutron cross sections, 21-group gamma cross sections, and gamma production cross sections and heating factors were generated based on a two-dimensional full core RZ model using the $\mathrm{MC}^{2}-3$ code. The coupled neutron and gamma heating calculations were done in several steps. The neutron flux was first calculated by solving an eigenvalue problem using the triangular-z finite difference option of the DIF3D code (Derstine, 1984). Using the calculated neutron flux and the gamma production cross sections, the photon source distribution induced by neutron reactions was computed with the GAMSOR code (Hill, 1988). With this calculated gamma source distribution, the gamma flux was calculated by solving a fixed source problem using the DIF3D code. Using the calculated neutron and gamma fluxes and the heating factors, the distributions of neutron, gamma, and total heating rates were calculated with the SUMMAR 
module of DIF3D. These heating rate distributions were normalized such that the total heating rate (i.e., the sum of neutron and gamma heating rates) is equal to the rated power.

Using the pin power distributions, whole-core temperature calculations were performed using the sub-channel analysis code SE2-ANL (Yang and Yacout, 1995). The SE2-ANL code is a modified version of the multi-assembly, steady-state sub-channel analysis code SUPERENERGY-2 (Basehore and Todreas, 1980). The coolant inlet and bulk outlet temperatures were set to $355^{\circ} \mathrm{C}$ and $510{ }^{\circ} \mathrm{C}$, respectively. The average flow rate was determined such that the average temperature rise in coolant across the core is $155^{\circ} \mathrm{C}$. Orifice zoning of assemblies and flow allocation to the assemblies in each orifice zone were iteratively determined with the overall goal of equalizing the accrual of fuel pin damage and thus pin reliability. The

fuel assembles were grouped into five orifice zones, considering the assembly power levels and the fuel management scheme. The non-fueled assemblies were grouped into four orifice zones. The assembly flow rates in non-fueled orifice zones were determined to be proportional to the assembly power to yield a uniform coolant outlet temperature. A separate orifice zone was assigned to the target assemblies. The assembly flow rates in individual orifice zones were iteratively determined such that the peak 2-sigma cladding mid-wall temperatures of individual fuel assemblies were equalized over the cycle. Hot channel factors for PRISM design (Vilim, 1985) were used for 2-sigma cladding and fuel temperature calculations.

\subsection{MA Transmutation Performance}

The transmutation performance of the target design was estimated under the assumption that the bred Pu and MAs in target assemblies would be recycled into the first-stage FR and the remaining MAs would be sent to the second-stage ADS if the total amount of recovered MA was larger than the capacity of target assemblies. It was also assumed that Pu and MA are recovered 
in two separate production streams. The recovered Pu from target assemblies is mixed with the recovered $\mathrm{U}$ and Pu from the discharged fuels and recycled into the driver fuels. The recovered MA from the discharged fuels of both driver fuel and target assemblies is recycled back into the target assemblies.

The core residence time of target assemblies was one burn cycle, which was constrained by the peak cladding inner wall temperature. Based on the results from the equilibrium cycle analysis of the first-stage FR with 18-month cycle length and 90\% capacity factor, a loading scheme of six target assemblies was selected to minimize the buildup of MAs in the first-stage FR core at the equilibrium state.

Table 1 shows the MA contents in discharged driver fuels and the TRU contents in target assemblies at the equilibrium state. A total amount of $17.88 \mathrm{~kg}$ of MA is loaded in the target assemblies, whereas $19.62 \mathrm{~kg}$ of MA is recovered from discharged drivers and targets. Therefore, the amount of MA to be sent to the ADS is $1.74 \mathrm{~kg}$. After one cycle irradiation, the remaining MA and the Pu generated in the target assemblies are $9.16 \mathrm{~kg}$ and $3.20 \mathrm{~kg}$, respectively. A transmutation rate of $48.8 \%$ and an absolute transmutation amount of $8.72 \mathrm{~kg}$ are obtained with six target assemblies. It was found that the total amount of transmuted MA is saturating with increasing number of target assemblies. When twelve target assemblies were used, the MA transmutation rate was roughly $8.72 \mathrm{~kg} / \mathrm{cycle}$ and higher mass actinides were increased due to the successive neutron captures.

The results from the equilibrium cycle analysis show that the use of moderated target assemblies could effectively reduce the amount of MAs to be sent to the second-stage ADS. Using the same loading scheme of six target assemblies, non-equilibrium cycle-by-cycle analyses were performed to study the overall MA transmutation performance of the first-stage 
FR core over the assumed plant lifetime of 60 years. It was assumed that a target assembly would be fabricated only when the recovered amount of MAs is sufficient to fabricate at least one assembly. Based on the available amount of recovered MA, the target assemblies were loaded in the core from the 9-th cycle. After one irradiation cycle in the core, six target assemblies were discharged and sent to the reprocessing plant. Considering the reprocessing and fabrication times, it was assumed that the MA in the target and driver fuel assemblies discharged at the end of n-th cycle would be recycled to the core at the beginning of $(n+2)$-th cycle. Since the amount of recovered MA varied with burn cycles, some MA pins were replaced with LLFP pins when the available MA was less than the MA loading in the reference design of target assembly. Total one hundred and ninety-two target assemblies were loaded in the core over an assumed plant lifetime of 60 years.

Fig. 7 presents the accumulated amount of MA in the first-stage FR core as a function of burn cycles. Without MA recycling in the FR, $533.0 \mathrm{~kg}$ of MA and $395.7 \mathrm{~kg}$ of LLFP were accumulated for the assumed plant lifetime of 60 years. Note that only Tc and I were included in the accumulated LLFP. With the use of 192 target assemblies, overall transmutation fractions of 88.6\% and 36.1\% were obtained for MA and LLFP, respectively. It can be seen that the MA produced in each cycle can be consumed in six target assemblies from cycle 9 to cycle 38. The inventory of MA left at the end of plant lifetime is the MA remaining in the target assemblies discharged at the end of cycles 39 and 40, which have not been recycled. On the other hand, LLFP was produced more in the core than consumed in six target assemblies, and thus the accumulation increases with burnup cycles. These results indicate that MA can be more effectively transmuted than LLFP with the current design of moderated MA target assembly. This is due to the relatively large loading of MA than that of LLFP. The MA and LLFP 
inventories at the end of plant lifetime are $61.0 \mathrm{~kg}$ and $253.0 \mathrm{~kg}$, respectively, and they need to be burned in the second-stage ADS.

\subsection{Kinetic Parameters and Shutdown Margins}

The core reactivity coefficients and kinetics parameters as well as the reactivity control requirements and shutdown margins were evaluated for the equilibrium core loaded with six target assemblies. The results summarized in Tables 2 and 3 showed that the use of MA target assemblies in the reflector region would not affect the safety characteristics of the first-stage FR. The moderated target assemblies increase the prompt neutron lifetime from $0.342 \mu$ s to $0.466 \mu \mathrm{s}$, and reduce the sodium void worth from $5.788 \$$ to $5.407 \$$. These small improvements are due to the softened spectrum caused by the moderator in the target assemblies. On the other hand, the Doppler coefficient, axial and radial expansion coefficients, and fuel density coefficient become slightly less negative due to the change in fuel composition. In addition, the integral reactivity parameters for the quasi-static reactivity model (Wade and Fujita, 1989) showed that the passive safety features of the first-stage FR (Lin et al., 2016b) remained unchanged.

\subsection{Sub-channel Thermal-hydraulics Analyses}

To assess the power peaking effects induced by the moderated target assembly, two heating calculations were performed: one with no target assembly and the other with moderated target assemblies. The core configurations for the DIF3D models were extracted from the output of the REBUS-3 fuel cycle analysis of the first-stage FR. The beginning of cycle (BOC) and end of cycle (EOC) configurations of the cycle 16 were analyzed. The pin power distributions of the case with the moderated target assemblies were calculated by superimposing the local pin power factors in the target and adjacent fuel assemblies determined from MCNP6 calculations with 
heterogeneous assembly geometries discussed in Section 2.3, on the reconstructed pin power distributions from the DIF3D calculations with homogenized assemblies.

Fig. 8 shows the one-third core configuration of the first-stage FR loaded with two target assemblies in the reflector zone and the associated assembly numbers to be used in presenting the calculation results later. Fig. 9 shows the assembly power distributions at BOC and EOC of the cycle 16. The left hand side (LHS) figure is for the core with no target assembly and the right hand side (RHS) figure is for the core with the target assemblies loaded at BOC of the cycle 16. It can be seen from Fig. 9 that the moderated target assemblies reduce the power production in the assemblies near the target assemblies and increase the power production in the assemblies far from the target assemblies. This power shift mitigates the local power peaking effects induced by the moderated target assemblies. The combined effects of the increased pin peaking factor and the decreased assembly power result in a decrease in the peak linear power in the fuel assemblies adjacent to target assemblies. In the target assemblies, the power production increases from BOC to EOC because of the fissile material build-up in the MA target pins. In addition, the gamma rays produced by the fission reactions in the target assemblies are transported to the nearby reflectors, where the gamma heating is the dominant heat source. Therefore, the power levels in reflectors are slightly increased as shown in Fig. 9.

Fig. 10 compares the radial flux distributions around a target assembly in the assembly position 66 in Fig. 8 for the two core configurations. It can be seen that the target assembly reduces the fast flux in its neighboring fuel assemblies, $\sim 15 \%$ in the next assembly. The fast neutrons leaking from the next fuel assembly are moderated in the target assembly by $\mathrm{ZrH}_{1.6}$ moderator. Because of the thermal neutron filter pins at the interfaces next to fuel assemblies, most of the moderated neutrons are absorbed in the target assembly and only a small fraction can 
be transported back to the adjacent fuel assemblies. Consequently, the moderated target assembly acts like a fast neutron sink and leads to a flux depression in the neighboring fuel assemblies.

Fig. 11 shows the maximum 2-sigma cladding inner wall temperatures for the core configurations of the cycle 16 without and with target assemblies. At BOC, in both core configurations, the maximum 2-sigma cladding inner wall temperature occurs at the outer core assemblies in the eighth row. At EOC, the peak temperature moves to the middle core assemblies in the sixth row for the core with no target assembly, while it moves to the inner core assemblies in the second row for the core with target assemblies. The overall maximum 2-sigma cladding inner wall temperature during the cycle is $648.4{ }^{\circ} \mathrm{C}$ in the core with no target assembly and 649.2 ${ }^{\circ} \mathrm{C}$ in the core with moderated target assemblies. These peak temperatures satisfy the imposed design limit of $650^{\circ} \mathrm{C}$ discussed in Section 2.2.

Fig. 12 shows the minimum 2-sigma margins to the fuel melt for each assembly for the cases without and with target assemblies. In both cases, the minimum 2-sigma margin to the fuel melt among all the assemblies occurs in the outer core assemblies in the eighth row at BOC, and it moves to the middle core assemblies in the sixth row at EOC. The minimum 2-sigma margin to fuel melt is $151.6{ }^{\circ} \mathrm{C}$ in the case with no target assembly and $142.4^{\circ} \mathrm{C}$ in the case with target assemblies. These results indicate that the peak fuel temperature in both cases has a significant margin of $\sim 150^{\circ} \mathrm{C}$ to the fuel melting temperature, which is about $\sim 1100^{\circ} \mathrm{C}$.

Fig. 13 shows the pin-bundle pressure drops of fuel and target assemblies. The height of pin bundle is set as $381.6 \mathrm{~cm}$, which includes the height of active core, fission gas plenum, lower shield and end plug (Lin et al., 2015, 2016a, 2016b). The maximum pressure drop across the pin bundle is about $0.43 \mathrm{MPa}$ in the case with no target assembly and about $0.45 \mathrm{MPa}$ in the case with target assemblies. The pin-bundle pressure drops of the first-stage FR are slightly higher 
than the pressure drops in the Advanced Burner Reactor (ABR) design, from which the firststage FR core design started. The maximum pin-bundle pressure drop of ABR is $0.38 \mathrm{MPa}$ (Yang et al., 2008; Kim and Yang, 2009). The thicker pin design of the first-stage FR core results in a decreased flow area in the fuel assembly and hence the flow velocity is increased. In addition, the increased core height in the FR also contributes to the higher pin bundle pressure drops.

\section{Fuel Cycle Performance}

The fuel cycle performance of the two-stage fuel cycle option with moderated MA target assemblies was evaluated using the reference FR core and ADS blanket designs (Lin et al., 2016a, 2016b). Using the MA recovered from the first-stage FR, the equilibrium cycle calculation was performed for the second-stage ADS. In the equilibrium cycle model of REBUS3, the HM recovered from discharged ADS fuels was used as the primary HM feed and the MAs recovered from target assemblies and the surplus $\mathrm{Pu}$ of the first-stage FR were used as the external feed to make up for the TRU consumed by fission. The isotopic composition of the recovered TRU at equilibrium cycle is presented in Table 4. It is noted that the use of MA target assemblies in the first-stage FR increases the fraction of the high mass actinides in the external feed stream. This is mainly due to the successive neutron captures of actinides in moderated target assemblies. A significant difference is observed in the fraction of $\mathrm{Cm}-244$ which is mainly produced by the $(n, \gamma)$ reaction of Am-243 via $\beta$ decay of Am-244.

Table 5 presents the equilibrium cycle performance of the ADS blanket of the two-stage

fuel cycle option with MA target assemblies in the first-stage FR. In the equilibrium core, the HM inventory at BOEC required to achieve the desired multiplication factor of 0.97 is $3062 \mathrm{~kg}$. 
The volume fractions of fuel particles in the charged fuel are $19.4 \%, 26.2 \%$, and $29.1 \%$ in the inner, middle and outer core zones, respectively. Compared to the second-stage ADS of the fuel cycle option with no target assembly in FR (Lin et al., 2016a, 2016b), the HM inventory at BOEC is reduced from $4208 \mathrm{~kg}$ to $3062 \mathrm{~kg}$ because of the increased amount of Pu due to target assemblies. The reduced amount of fuel inventory increases the average discharge burnup to $25.4 \%$ from $19.4 \%$. The peak fast fluence for the ADS is $3.98 \times 10^{23} \mathrm{n} / \mathrm{cm}^{2}$, which is within the design constraint of HT-9 cladding. The burnup reactivity loss is $3.2 \%$ with a six-month cycle design. The power distribution is flattened by enrichment zoning, and as a result, power peaking factors for each zone are practically the same. The power peaking factors are similar between BOEC and EOEC, but during burnup, power peaking is shifted from the outer to the inner zone due to the increased spallation neutron source to maintain the same power level.

Using the performance parameters of the FR with MA target assemblies and the corresponding second-stage ADS, the mass flow data at the equilibrium state were assessed for a nuclear fleet of 100 GWe-yr electricity production. TRU are recovered in the first-stage FRs at a rate of $3 \mathrm{~kg} / \mathrm{GWe}$-yr, and they are consumed by fission in the second-stage ADSs at a rate of $1045 \mathrm{~kg} / \mathrm{GWe}$-yr. Based on the TRU production and consumption rates, the electricity sharing between FRs and ADSs in the nuclear fleet was estimated to be $99.7 \%$ to $0.3 \%$. Compared to the two-stage FR/ADS fuel cycle option with no target assembly in FR (Lin et al., 2016a, 2016b), the electricity sharing of ADS is reduced to $0.3 \%$ from $1.9 \%$. The decrease in demand for ADS results from the reduced amount of MA from the first-stage FR.

Table 6 shows the mass flow data at equilibrium state estimated for a 100 GWe-yr electricity generation. In this table, the signs of $(-)$ and $(+)$ present the feed to and the product from each system, and masses in each column show the mass flow per each technology to 
support each stage. At the equilibrium state, the FR is fueled with 1045.7 MT of U, 159.2 MT of Pu and 3.3 MT of MA, whereas 944.6 MT of U, 159.5 MT of Pu, 3.6 MT of MA are recovered from the reprocessing facility. During the reprocessing/separation and fresh fuel fabrication processes, 11.2 MT and 2.4 MT of nuclear materials are lost to the waste stream, respectively. The masses in the last column indicate the required (-) or produced $(+)$ nuclear material per year needed to generate 100 GWe-yr of electricity. Results show that approximately 103.2 MT of natural $U$ would be required for sustaining the two-stage FR/ADS fuel cycle option with MA target assemblies in FR. Since the Pu and MA are continuously recycled, this fuel cycle option does not release Pu or MA except for the losses from the fuel fabrication and separation. For the overall fuel cycle, there are 88.9 MT of FPs and 13.6 MT of HM sent to the repository.

\section{Conclusions}

In order to provide supporting information for the E\&S study, a two-stage, fast spectrum fuel cycle option consisting of FR and ADS was recently proposed to enhance the natural resource utilization and reduce the nuclear waste to be sent to the geological repository (Lin, et al., 2016a, 2016b). In this two-stage fuel cycle option, the recovered MA from the discharged fuel of the first-stage FR is sent to the second-stage ADS directly. In order to minimize the required number of ADSs in the proposed two-stage fuel cycle option by reducing the amount of MA sent to the second-stage ADS, a strategy to incinerate MA in the first-stage FR has been developed by deploying moderated MA target assemblies.

In order to minimize the local power peaking problem induced by moderated target assemblies, the target assemblies were loaded in the reflector region. Using MA-40Zr target composition and $\mathrm{ZrH}_{1.6}$ moderator, an optimum MA target assembly design was developed. To 
maximize the MA destruction within the practical thermal design limits on the cladding inner wall temperature, an optimum volume fraction of moderator was determined to be $39.2 \%$. The resulting target assembly contains 169 pins of $9.5 \mathrm{~mm}$ diameter and has the same assembly dimensions as the driver fuel assembly. Twenty-four MA target pins, one hundred and twentyseven moderator pins, nine technetium (Tc) pins and nine calcium iodide $\left(\mathrm{CaI}_{2}\right)$ pins are almost evenly distributed in the target assembly. Long-lived fission product pins are used as thermal neutron filters to reduce the local power peaking in the adjacent fuel assemblies due to the thermal neutron leakage from the moderated target assembly.

The use of six MA target assemblies in the first-stage FR reduced the amount of MA to be sent to ADS by a factor of six compared to the two-stage fuel cycle without MA recycling in FR. With no recycling of recovered MA in FR, the feed rate of MA and surplus Pu from FR to ADS was $18 \mathrm{~kg} / \mathrm{GWe}-\mathrm{yr}$ and the TRU consumption rate in ADS was $958 \mathrm{~kg} / \mathrm{GWe}-\mathrm{yr}$ (Lin et al., 2016a, 2016b). When the recovered MA is partially incinerated in FR using moderated MA target assemblies, the feed rate of MA and surplus Pu to ADS was reduced to $3 \mathrm{~kg} / \mathrm{GWe}-\mathrm{yr}$ and the TRU consumption rate in ADS was increased to $1045 \mathrm{~kg} / \mathrm{GWe}-\mathrm{yr}$. As a result, the electricity sharing of ADS in a nuclear park composed of FRs and ADSs was reduced to $0.3 \%$ from $1.9 \%$. In a nuclear fleet of 100 GWe-yr electricity production, about 103.2 MT of natural uranium is required to support this two-stage fuel cycle option and there are 88.9 MT of FP and 13.6 MT of HM sent to the repository.

Detailed sub-channel thermal-hydraulics analysis showed that the FR core with six moderated target assemblies in the reflector region satisfies all the imposed design limits on the peak cladding inner wall and fuel centerline temperatures. The overall maximum 2-sigma cladding inner wall temperature during the cycle is $648.4{ }^{\circ} \mathrm{C}$ in the core with no target assembly 
and $649.2{ }^{\circ} \mathrm{C}$ in the core with moderated target assemblies. These peak temperatures satisfy the imposed design limit of $650{ }^{\circ} \mathrm{C}$. The minimum 2-sigma margin to fuel melt is $151.6{ }^{\circ} \mathrm{C}$ in the case with no target assembly and $142.4{ }^{\circ} \mathrm{C}$ in the case with target assemblies. These results indicate that the peak fuel temperature in both cases has a significant margin of $\sim 150{ }^{\circ} \mathrm{C}$ to the fuel melting temperature, which is about $\sim 1100{ }^{\circ} \mathrm{C}$.

The calculated core reactivity coefficients and kinetics parameters as well as the reactivity control requirements and shutdown margins confirmed that the presence of target assemblies would not have a significant impact on the safety parameters. The moderated target assemblies increase the prompt neutron lifetime from $0.342 \mu$ s to $0.466 \mu$ s, and reduce the sodium void worth from $5.788 \$$ to $5.407 \$$. These small improvements are due to the softened spectrum caused by the moderator in the target assemblies. On the other hand, the Doppler coefficient, axial and radial expansion coefficients, and fuel density coefficient become slightly less negative due to the change in fuel composition. In addition, the integral reactivity parameters for the quasi-static reactivity model showed that the passive safety features of the first-stage FR remained unchanged.

These results indicate that the use of MA target assemblies in the first-stage FR reduces the amount of TRU to be sent to ADS and thus the number of ADSs in the second stage without deteriorating safety characteristics.

\section{Acknowledgments}

This research was performed using funding received from the DOE Office of Nuclear Energy's Nuclear Energy University Program. The authors would like to thank Mr. Jacob Hader, Mr. Puran Deng and Mr. Gang Yang from the School of Nuclear Engineering at Purdue 
University for their supporting calculations in reactivity feedback coefficients, coupled neutron and gamma heating, and sub-channel thermal-fluidic analysis, respectively. 


\section{References}

Basehore, K. L. and Todreas, N. E., 1980. SUPERENERGY-2: A multi-assembly, steady-stage computer code for LMFBR core thermal-hydraulic analysis. Pacific Northwest Laboratory, PNL3379.

Carmack, J. and Pasamehmetoglu, K. O., 2008. Review of transmutation fuel studies. Idaho National Laboratory, INL/EXT-08-13779.

Derstine, K. L., 1984. DIF3D: A code to solve one-, two, and three-dimensional finite difference diffusion theory problem. Argonne National Laboratory, ANL-82-64.

Gibson, J. K. et al., 1994. The neptunium-iron phase diagram. Journal of Nuclear Materials, 211, 215-222.

Hill, R. N., 1988. Coupled neutron-gamma heating calculations. Private Communication, Argonne National Laboratory.

IAEA, 2010. Status of minor actinide fuel development. International Atomic Energy Agency, Nuclear Energy Series NF-T-4.6.

IAEA, 2011. Generic procedures for response to a nuclear or radiological emergency at TRIGA research reactors. International Atomic Energy Agency.

Inagaki, O., Nakamura, K., and Ogata, T., 2013. Progress in understanding of fuel-cladding chemical interaction in metal fuel. International Conference on Fast Reactors and Related Fuel Cycles, Paris, France, March 4-7, 2013.

Kim, T. K., Yang, W. S., Grandy, C., and Hill, R. N., 2009. Core design studies for a $1000 \mathrm{MWt}$ advanced burner reactor. Annals of Nuclear Energy, 36, 331-336.

LANL, 2014. MCNP6TM user's manual, code version 6.1.1beta. Los Alamos National Laboratory, LA-CP-14-00745, Rev. 0.

Lawrence, R. D., 1983. The DIF3D nodal neutronics option for two- and three-dimensional diffusion theory calculations in hexagonal geometry. Argonne National Laboratory, ANL-83-1.

Lee, C. H. and Yang, W. S., 2011. MC $^{2}$-3: Multigroup cross section generation code for fast system analysis. Argonne National Laboratory, ANL/NE-11-41.

Leggett, R. D. and Walters, L. C., 1993. Status of LMR fuel development in the United States of America. Journal of Nuclear Materials, 204, 23.

Lin, C. S., Hader, J. S., Park, T. K., and Yang, W. S., 2015. Design of a low enriched uranium fast reactor for maximum fuel resource utilization. Trans. Am. Nucl. Soc., 113, 1103-1106.

Lin, C. S., Hader, J. S., Park, T. K., and Yang, W. S., 2016a. A two-stage fast spectrum fuel cycle option for optimum resource utilization and waste management. Proc. of ICAPP 2016, San Francisco, California, April 17-20, 2016. 
Lin, C. S., Park, T. K., and Yang, W. S., 2016b. Fast reactor and accelerator driven system core design studies for two-stage fast spectrum fuel cycle option. Nucl. Tech. (Accepted).

Moore K. and Young, W., 1968. Phase studies of the $\mathrm{Zr}-\mathrm{H}$ system at high hydrogen concentrations. Journal of Nuclear Materials, 27, 316-324.

NEA, 2012. Homogeneous versus heterogeneous recycling of transuranics in fast nuclear reactors. Organization for Economic Cooperation and Development, Nuclear Energy Agency, NEA No. 7077.

Palmiotti, G., Lewis, E. E., and Carrico, C. B., 1995. VARIANT: Vibrational anisotropic nodal transport for multi-dimensional Cartesian and hexagonal geometry calculations. Argonne National Laboratory, ANL-95/40.

Smith, M. A. et al., 2013. VARI3D \& PERSENT: Perturbation and sensitivity analysis. Argonne National Laboratory, ANL/NE-13/8.

Toppel, B. J., 1983. A user's guide to the REBUS-3 fuel cycle analysis capability. Argonne National Laboratory, ANL-83-2.

Tsai, H. C. 1990. Fuel/Cladding compatibility in irradiated metallic fuel pins at elevated temperatures. Proc. 1990 International Fast Reactor Safety Meeting, Snowbird, UT, August 1216.

Vilim, R. B., 1985. Reactor hot spot analysis. Private Communication, Argonne National Laboratory.

Wade, D. C. and Fujita, E. K., 1989. Trends versus reactor size of passive reactivity shutdown and control performance. Nucl. Sci. Eng., 103, 182.

Waltar, A. E., Todd, D. R., and Tsvetkov, P. V., 2012. Fast spectrum reactors. Springer.

Wigeland, R et al., 2014. Nuclear fuel cycle evaluation and screening-final report. US DOE, FCRDFCO-2014-000106.

Yang, W. S. and Yacout, A. M., 1995. Assessment of the SE2-ANL Code Using EBR-II Temperature Measurements. Proc. 7th International Meeting on Nuclear Reactor Thermal Hydraulics, NUREG/CP-0142, Saratoga Springs, New York, September 10-15.

Yang, W. S., Kim, Y., Hill, R. N., Taiwo, T. A., and Khalil, S., 2004. Long-Lived Fission Product Transmutation Studies. Nucl. Sci. Eng., 146, 291. 


\section{List of Tables}

\section{Table 1}

MA contents in discharged driver fuels and TRU contents in target assemblies at equilibrium state of FR.

\section{Table 2}

Kinetic parameters and reactivity coefficients of FRs with and without moderated target assemblies.

\section{Table 3}

Shutdown margins of primary and secondary control systems of FRs with and without moderated target assemblies.

\section{Table 4}

Isotopic composition of external feed for ADS of two-stage fuel cycle option with and without moderated target assemblies in FR.

\section{Table 5}

Equilibrium cycle performance of sodium-cooled ADS blanket design.

\section{Table 6}

Mass flow data of the two-stage fuel cycle option with moderated target assemblies (metric ton per 100 GWe-yr at equilibrium state).

\section{Captions of Figures}

Fig. 1. Radial core layout of 1000MWt sodium-cooled fast reactor concept.

Fig. 2. Effective one-group capture cross section of MA versus moderator to MA target volume ratio for four target pin designs.

Fig. 3. Normalized capture rate and one-group capture cross section of MA versus moderator to MA target volume ratio.

Fig. 4. Peak linear power after one irradiation cycle versus moderator volume fraction.

Fig. 5. Moderated target assembly layout (red: MA, blue: $\mathrm{ZrH}_{1.6}$, orange: Tc, and yellow: $\mathrm{CaI}_{2}$, Faces with LLFP target pins interface with driver fuels).

Fig. 6. Whole-core MCNP6 models: (a) without moderated target assembly; (b) with moderated target assembly.

Fig. 7. Accumulated amounts of MA and LLFP versus burn cycle of the first-stage FR core.

Fig. 8. One-third core configuration of first-stage FR with assembly numbering.

Fig. 9. Assembly power distributions (MWt) of first-stage FR without (left) and with target assemblies (right). 
Fig. 10. Radial flux distributions at core periphery without and with target assemblies.

Fig. 11. Maximum 2-sigma cladding inner wall temperatures $\left({ }^{\circ} \mathrm{C}\right)$ of first-stage FR core without (left) and with target assemblies (right).

Fig. 12. Minimum 2-sigma margins to fuel melt $\left({ }^{\circ} \mathrm{C}\right)$ of first-stage FR core without (left) and with target assemblies (right).

Fig. 13. Average pin bundle pressure drop (MPa) of first-stage FR core without (left) and with target assemblies (right). 


\section{Table 1}

MA contents in discharged driver fuels and TRU contents in target assemblies at equilibrium state of FR.

\begin{tabular}{|c|c|c|c|c|c|c|}
\hline \multirow{3}{*}{ Isotope } & \multirow{2}{*}{\multicolumn{2}{|c|}{ Discharged Drivers }} & \multicolumn{4}{|c|}{ Target Assemblies } \\
\hline & & & \multicolumn{2}{|l|}{$\mathrm{BOEC}^{\mathrm{a}}$} & \multicolumn{2}{|l|}{$\mathrm{EOEC}^{\mathrm{b}}$} \\
\hline & Mass, kg & Fraction, \% & Mass, kg & Fraction, \% & Mass, kg & Fraction, \% \\
\hline $\mathrm{Np}-237$ & 2.99 & 28.6 & 3.75 & 20.9 & 0.84 & 6.8 \\
\hline $\mathrm{Pu}-236$ & - & - & 0.00 & 0.0 & 0.00 & 0.0 \\
\hline Pu-238 & - & - & 0.00 & 0.0 & 2.23 & 18.0 \\
\hline Pu-239 & - & - & 0.00 & 0.0 & 0.36 & 2.9 \\
\hline Pu-240 & - & - & 0.00 & 0.0 & 0.14 & 1.1 \\
\hline $\mathrm{Pu}-241$ & - & - & 0.00 & 0.0 & 0.18 & 1.4 \\
\hline $\mathrm{Pu}-242$ & - & - & 0.00 & 0.0 & 0.29 & 2.3 \\
\hline Am-241 & 4.62 & 44.2 & 4.40 & 24.6 & 0.05 & 0.4 \\
\hline Am-242 & 0.18 & 1.7 & 0.17 & 1.0 & 0.00 & 0.0 \\
\hline Am-243 & 1.97 & 18.8 & 2.34 & 13.1 & 0.73 & 5.9 \\
\hline $\mathrm{Cm}-242$ & 0.20 & 1.9 & 0.24 & 1.4 & 0.52 & 4.2 \\
\hline $\mathrm{Cm}-243$ & 0.01 & 0.1 & 0.04 & 0.2 & 0.04 & 0.3 \\
\hline $\mathrm{Cm}-244$ & 0.46 & 4.4 & 5.15 & 28.8 & 5.18 & 41.9 \\
\hline $\mathrm{Cm}-245$ & 0.03 & 0.3 & 0.32 & 1.8 & 0.31 & 2.5 \\
\hline $\mathrm{Cm}-246$ & 0.00 & 0.0 & 1.47 & 8.2 & 1.49 & 12.1 \\
\hline MAs & 10.46 & & 17.88 & & 9.16 & \\
\hline TRU & 10.46 & & 17.88 & & 12.36 & \\
\hline
\end{tabular}

a BOEC: Beginning of Equilibrium Cycle

${ }^{\mathrm{b}}$ EOEC: End of Equilibrium Cycle 


\section{Table 2}

Kinetic parameters and reactivity coefficients of FRs with and without moderated target assemblies.

\begin{tabular}{|c|c|c|}
\hline Parameter (unit) & FR with targets & FR without Targets \\
\hline Delayed neutron fraction $\left(\beta_{\text {eff }}\right)$ & 0.00357 & 0.00357 \\
\hline Prompt neutron lifetime $(\mu \mathrm{s})$ & 0.466 & 0.342 \\
\hline Axial expansion coefficient $\left(\mathbb{\Phi} /{ }^{\circ} \mathrm{C}\right)$ & -0.079 & -0.082 \\
\hline Radial expansion coefficient $\left(\mathbb{\$} /{ }^{\circ} \mathrm{C}\right)$ & -0.215 & -0.221 \\
\hline Doppler coefficient $\left(\$ /{ }^{\circ} \mathrm{C}\right)$ & -0.146 & -0.148 \\
\hline Fuel density coefficient $\left(\mathbb{\$} /{ }^{\circ} \mathrm{C}\right)$ & -0.530 & -0.540 \\
\hline Structure density coefficient $\left(\mathbb{\$} /{ }^{\circ} \mathrm{C}\right)$ & 0.053 & 0.053 \\
\hline Sodium density coefficient $\left(\mathbb{\$} /{ }^{\circ} \mathrm{C}\right)$ & 0.0269 & 0.0285 \\
\hline Sodium void worth (\$) & 5.407 & 5.788 \\
\hline Sodium-voided Doppler coefficient $\left(\mathbb{\$} /{ }^{\circ} \mathrm{C}\right)$ & -0.094 & -0.092 \\
\hline
\end{tabular}




\section{Table 3}

Shutdown margins of primary and secondary control systems of FRs with and without moderated target assemblies.

\begin{tabular}{lllll}
\hline \multirow{2}{*}{ Parameter (unit) } & Primary & \multicolumn{2}{l}{ Secondary } \\
\cline { 2 - 5 } & With targets & $\begin{array}{l}\text { Without } \\
\text { targets }\end{array}$ & With targets & $\begin{array}{l}\text { Without } \\
\text { targets }\end{array}$ \\
\hline Number of control assemblies & 9 & 9 & 4 & 4 \\
Total worth (\$) & 20.03 & 20.49 & 9.78 & 9.81 \\
Worth with one stuck assembly (\$) & 17.01 & 17.38 & 7.01 & 7.75 \\
Control requirement (\$) & 5.26 & 4.19 & 1.62 & 1.66 \\
Shutdown margin $(\$)$ & 11.75 & 13.19 & 5.39 & 6.09 \\
\hline
\end{tabular}




\section{Table 4}

Isotopic composition of external feed for ADS of two-stage fuel cycle option with and without moderated target assemblies in FR.

\begin{tabular}{lll}
\hline Isotope & Without targets (\%) & With targets (\%) \\
\hline Np-237 & 29.6 & 6.8 \\
Pu-236 & 0.0 & 0.0 \\
Pu-238 & 0.0 & 18.0 \\
Pu-239 & 0.0 & 2.9 \\
Pu-240 & 0.0 & 1.1 \\
Pu-241 & 2.6 & 1.4 \\
Pu-242 & 0.0 & 2.3 \\
Am-241 & 44.1 & 0.4 \\
Am-242m & 1.7 & 0.0 \\
Am-243 & 16.5 & 5.9 \\
Cm-242 & 1.9 & 4.2 \\
Cm-243 & 0.1 & 0.3 \\
Cm-244 & 3.3 & 41.9 \\
Cm-245 & 0.2 & 2.5 \\
Cm-246 & 0.0 & 12.1 \\
Total & 100.0 & 100.0 \\
\hline
\end{tabular}




\section{Table 5}

Equilibrium cycle performance of sodium-cooled ADS blanket design.

\begin{tabular}{ll}
\hline Parameter & ADS \\
\hline Thermal power, MW & 840 \\
Cycle length, EFPD & 135 \\
Capacity factor, \% & 75 \\
BOEC heavy metal inventory, kg & 3062 \\
Fuel particle fraction, volume \% in matrix & \\
Inner zone & 19.4 \\
Middle zone & 26.2 \\
Outer zone & 29.1 \\
Multiplication factor & \\
BOEC & 0.97065 \\
EOEC & 0.93894 \\
Burnup reactivity loss, \% $\Delta \mathrm{k}$ & 3.2 \\
Core-average power density, kw/l & 247.6 \\
Power peaking factor at BOEC/EOEC & $1.51 / 1.51$ \\
Peak linear power, kW/m & \\
Inner zone & 36.1 \\
Middle zone & 34.4 \\
Outer zone & 35.0 \\
Average discharge burnup, atom \% & 25.4 \\
Peak fast fluence, $10^{23} \mathrm{n} / \mathrm{cm}{ }^{2}$ & 3.98 \\
Net TRU consumption rate, kg/year & 256 \\
Equilibrium loading, kg/year & \\
FR TRU & 256 \\
Recycled HM & 664 \\
Total HM & 920 \\
\hline
\end{tabular}




\section{Table 6}

Mass flow data of the two-stage fuel cycle option with moderated target assemblies (metric ton per 100 GWe-yr at equilibrium state).

\begin{tabular}{|c|c|c|c|c|c|c|c|c|}
\hline Stage & & 1 & & & 2 & & & \\
\hline Technology & & Fuel & $\mathrm{NPPT}^{\mathrm{a}}$ & Rep/Sep ${ }^{b}$ & Fuel & NPPT & Rep/Sep & sum \\
\hline Electricity, GWe-yr & & 99.7 & & & 0.3 & & & 100.0 \\
\hline & $\mathrm{NU}$ & -103.2 & & & & & & -103.2 \\
\hline Natural resource & Th & & & & & & & \\
\hline & DU & & & & & & & \\
\hline & $\mathrm{U}$ & $+1,045.7$ & $-1,045.7$ & & +0.0 & -0.0 & & 0.0 \\
\hline Products from fuel or & $\mathrm{Pu}$ & +159.2 & -159.2 & & +0.4 & -0.4 & & 0.0 \\
\hline & MA & +3.3 & -3.3 & & +0.6 & -0.6 & & 0.0 \\
\hline & $\mathrm{DF}$ & & $+1,209.0$ & $-1,209.0$ & & +1.0 & -1.0 & 0.0 \\
\hline & RU & -944.6 & & +944.6 & -0.0 & & +0.0 & 0.0 \\
\hline Products from Rep/Sep & $\mathrm{Pu}$ & -159.5 & & +159.5 & -0.3 & & +0.3 & 0.0 \\
\hline technology & MA & -3.3 & & +3.6 & -0.7 & & +0.4 & 0.0 \\
\hline & FP & -1.6 & & +90.2 & & & +0.3 & +88.9 \\
\hline Loss $^{\mathrm{c}}$ & & +2.4 & & +11.2 & +0.0 & & +0.0 & +13.6 \\
\hline
\end{tabular}

${ }^{\mathrm{a}} \mathrm{NPPT}=$ Nuclear Power Plant / Transmutation

${ }^{\mathrm{b}}$ Rep/Sep = Reprocessing / Separation

${ }^{c}$ Loss of U, Pu and MAs 


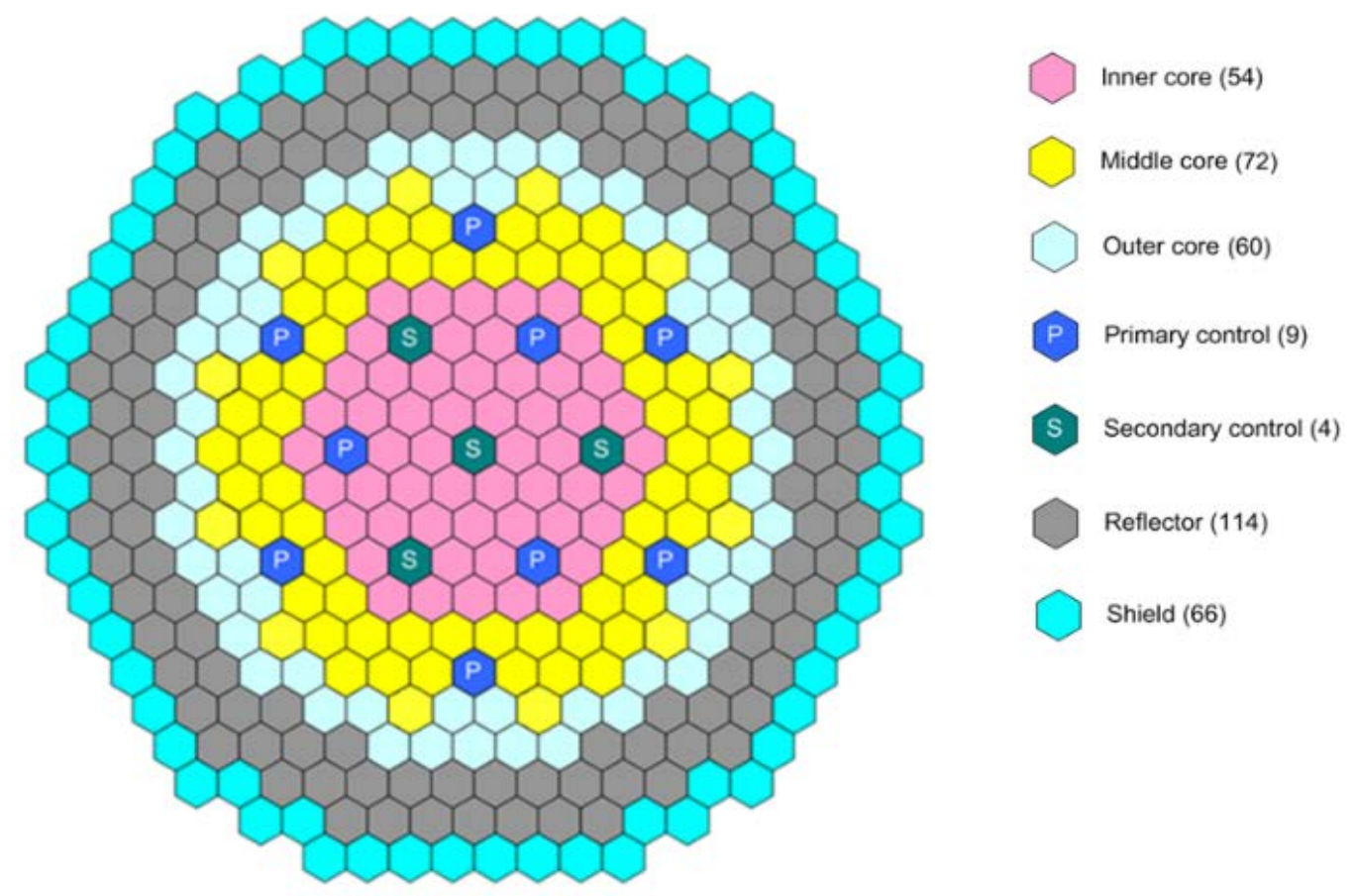

Fig. 1. Radial core layout of 1000MWt sodium-cooled fast reactor concept. 


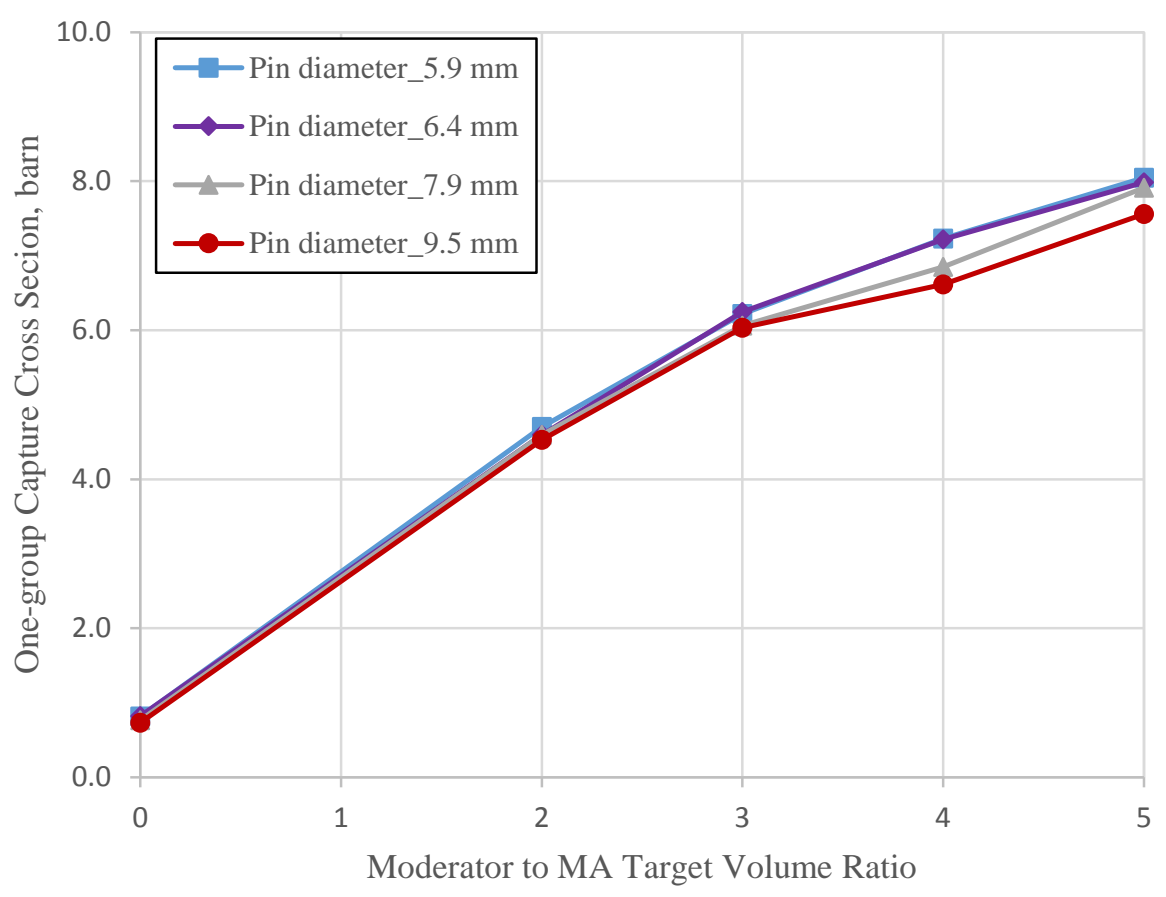

Fig. 2. Effective one-group capture cross section of MA versus moderator to MA target volume ratio for four target pin designs. 


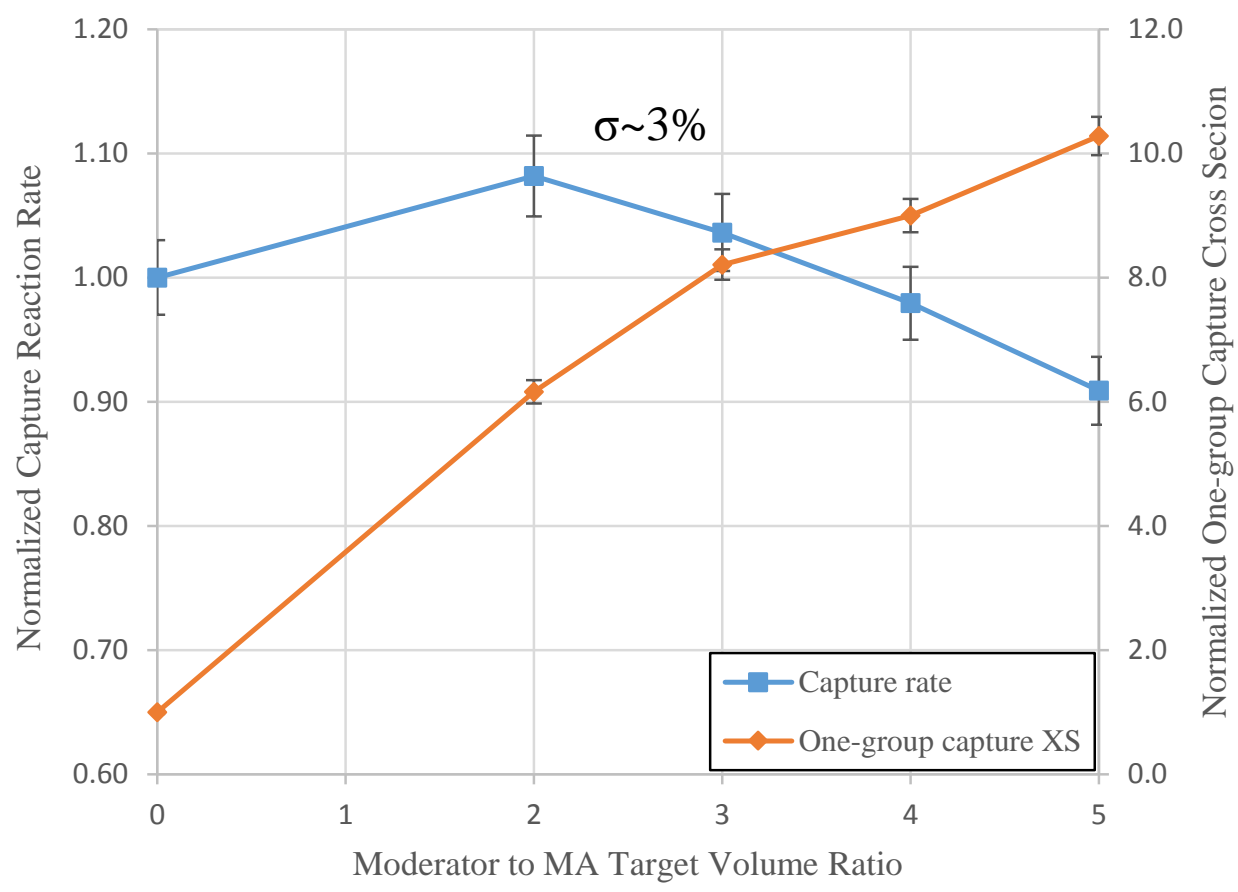

Fig. 3. Normalized capture rate and one-group capture cross section of MA versus moderator to MA target volume ratio (Pin diameter of $9.5 \mathrm{~mm}$ ). 


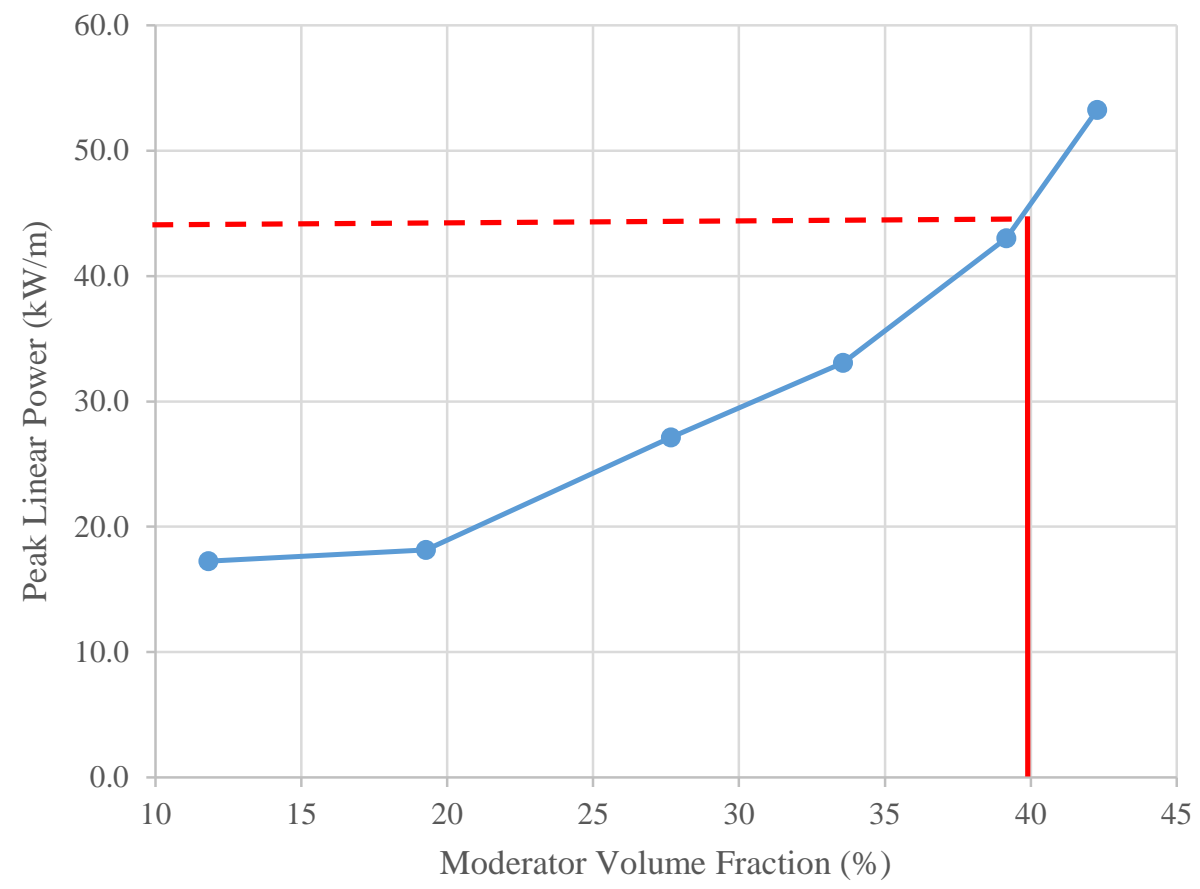

Fig. 4. Peak linear power after one irradiation cycle versus moderator volume fraction. 


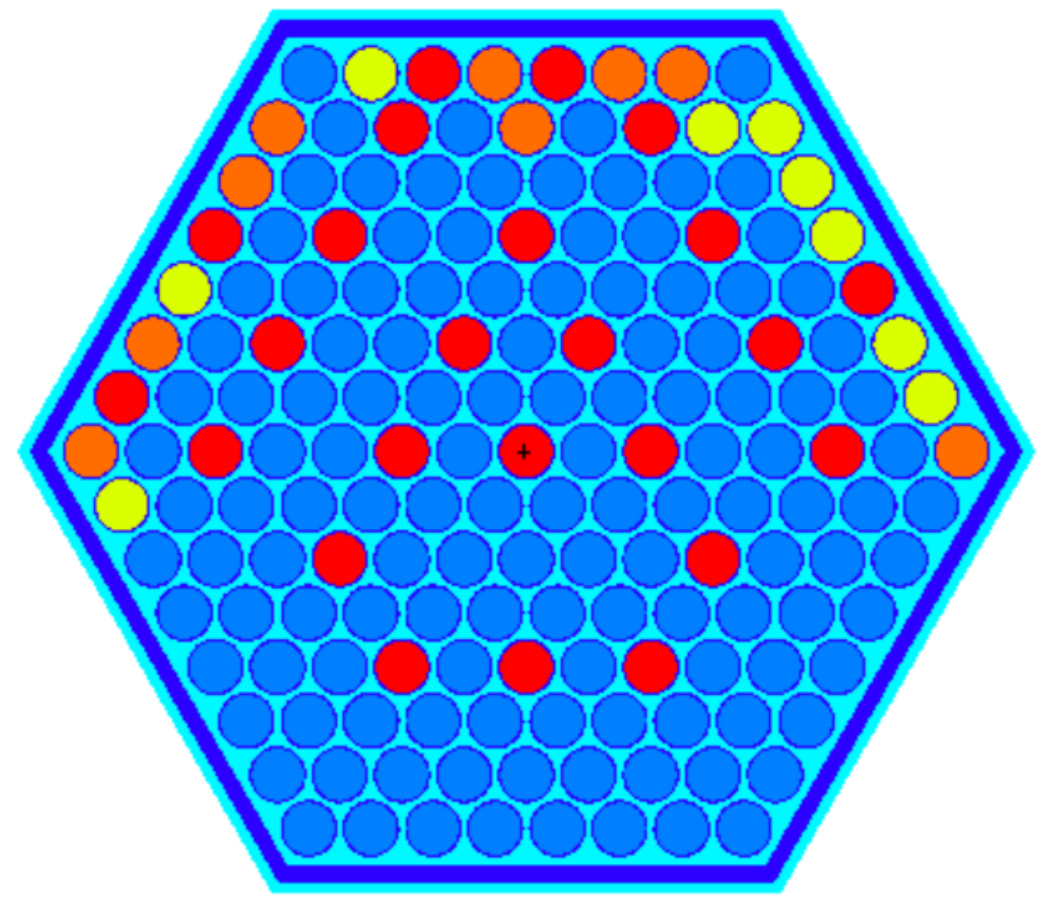

Fig. 5. Moderated target assembly layout (red: MA, blue: $\mathrm{ZrH}_{1.6}$, orange: Tc, and yellow: $\mathrm{CaI}_{2}$; Faces with LLFP target pins interface with driver fuels). 


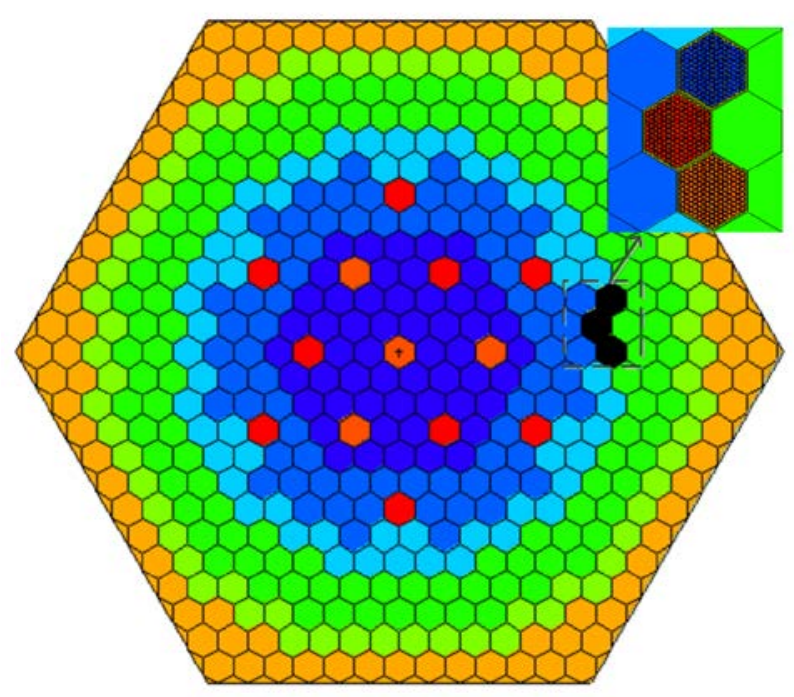

(a)

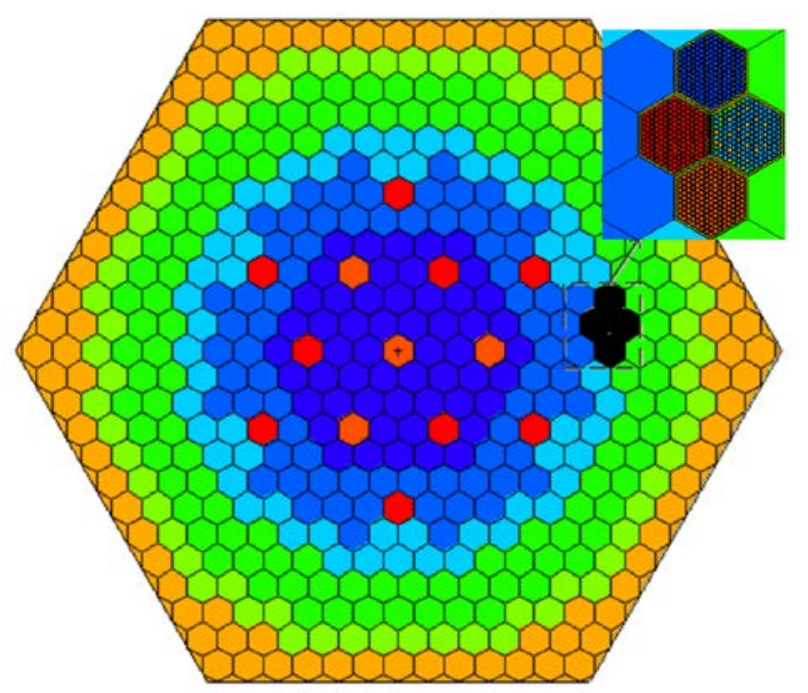

(b)

Fig. 6. Whole-core MCNP6 models: (a) without moderated target assembly; (b) with moderated target assembly. 


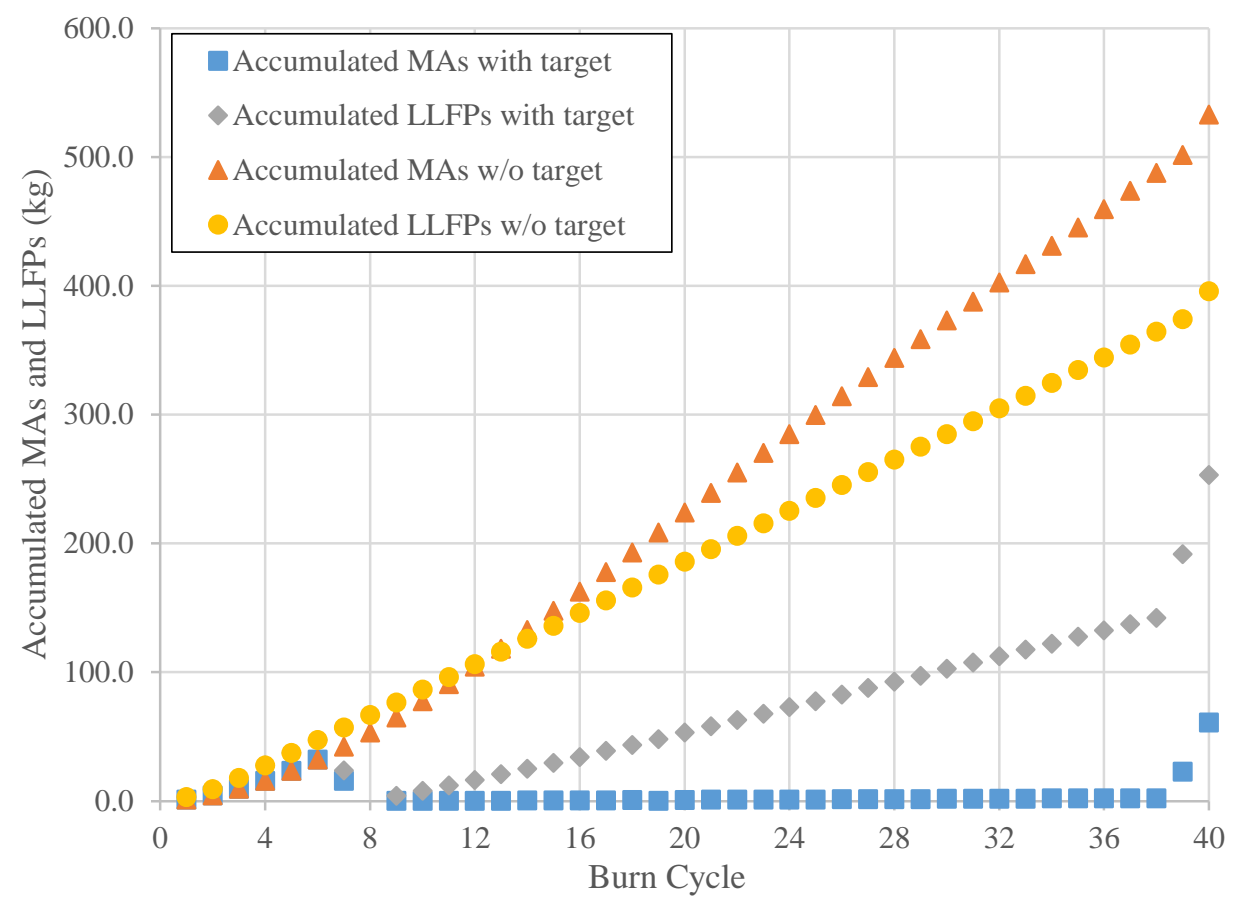

Fig. 7. Accumulated amounts of MA and LLFP versus burn cycle of the first-stage FR core. 


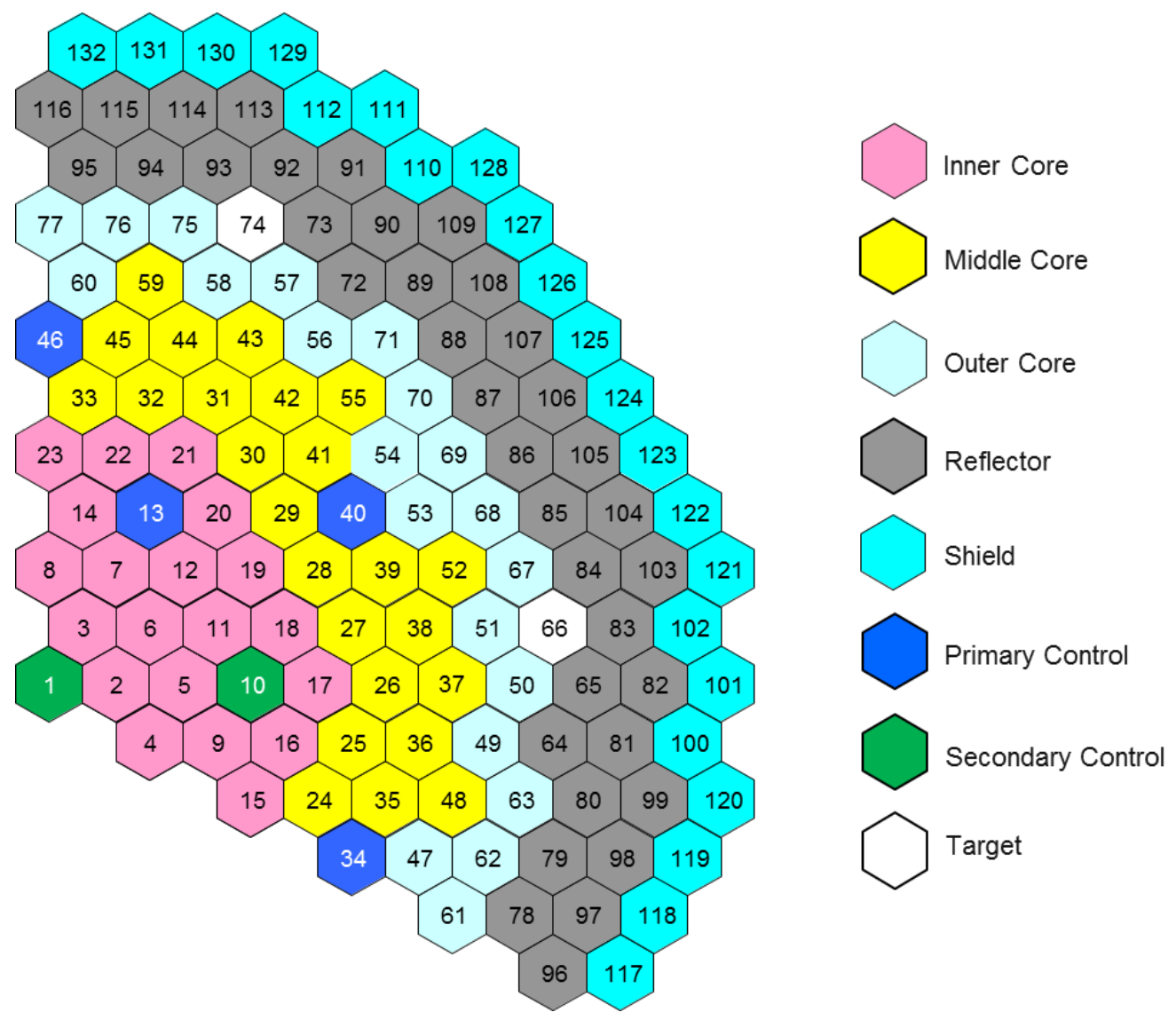

Fig. 8. One-third core configuration of first-stage FR with assembly numbering. 

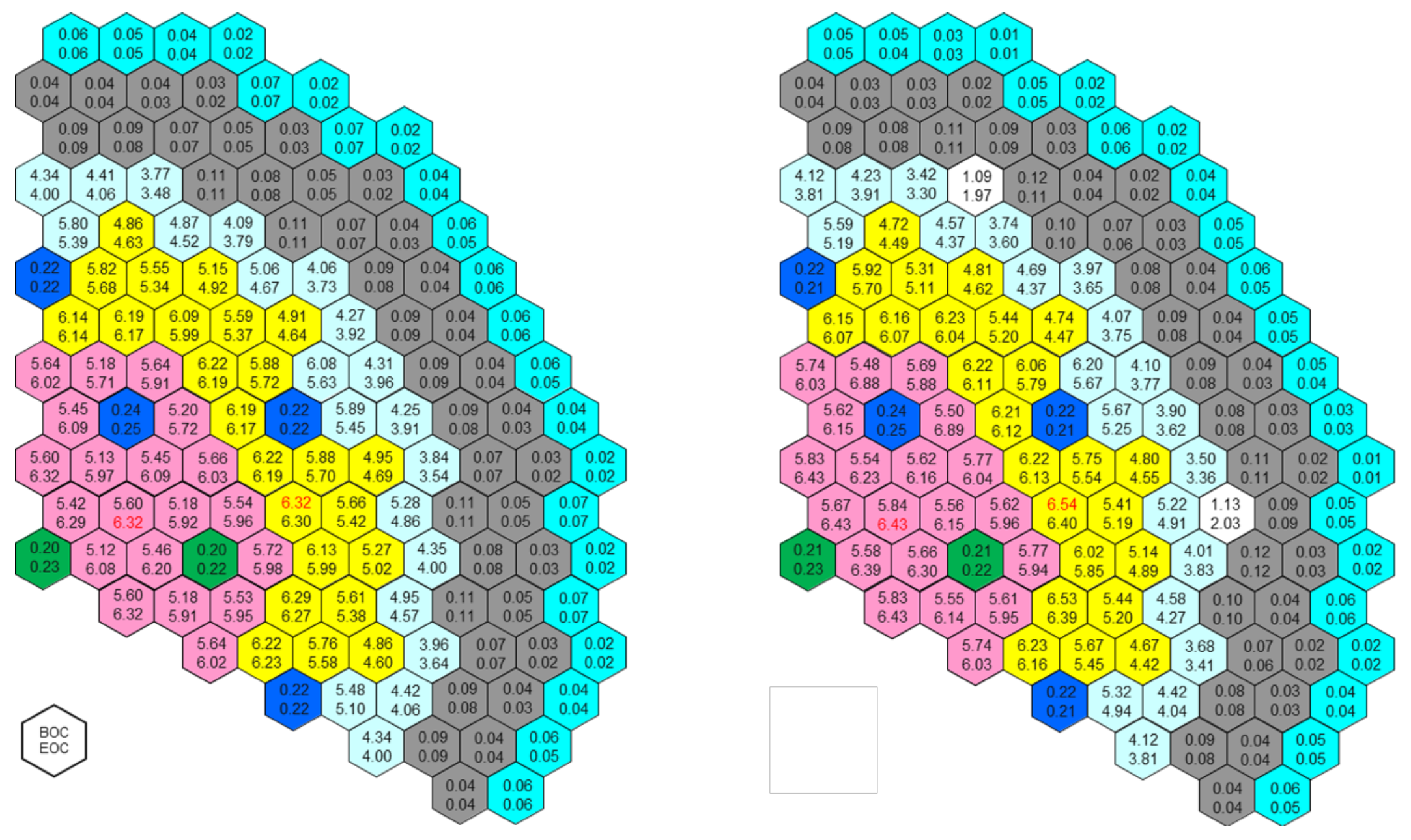

Fig. 9. Assembly power distributions (MWt) of first-stage FR without (left) and with target assemblies (right). 


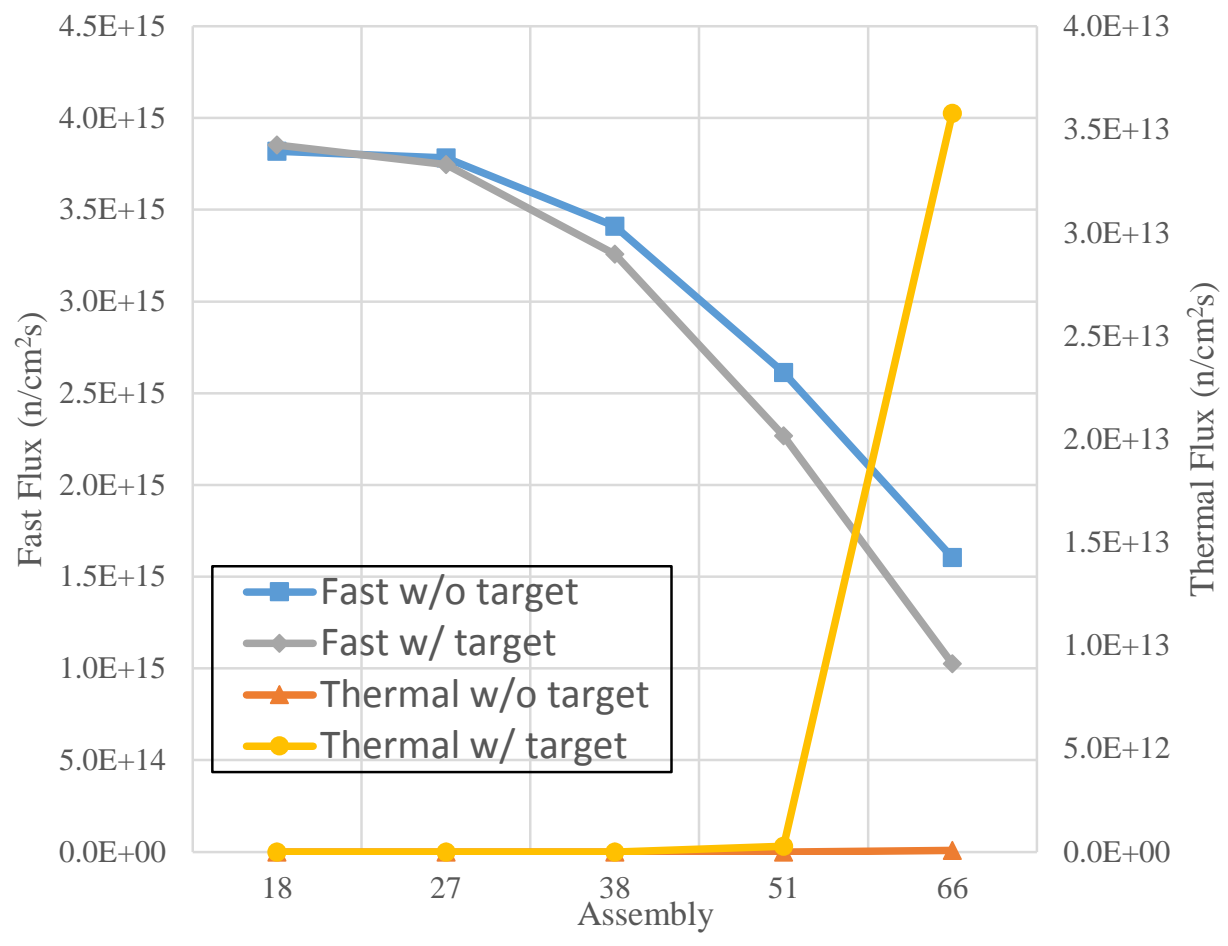

Fig. 10. Radial flux distributions at core periphery without and with target assemblies. 

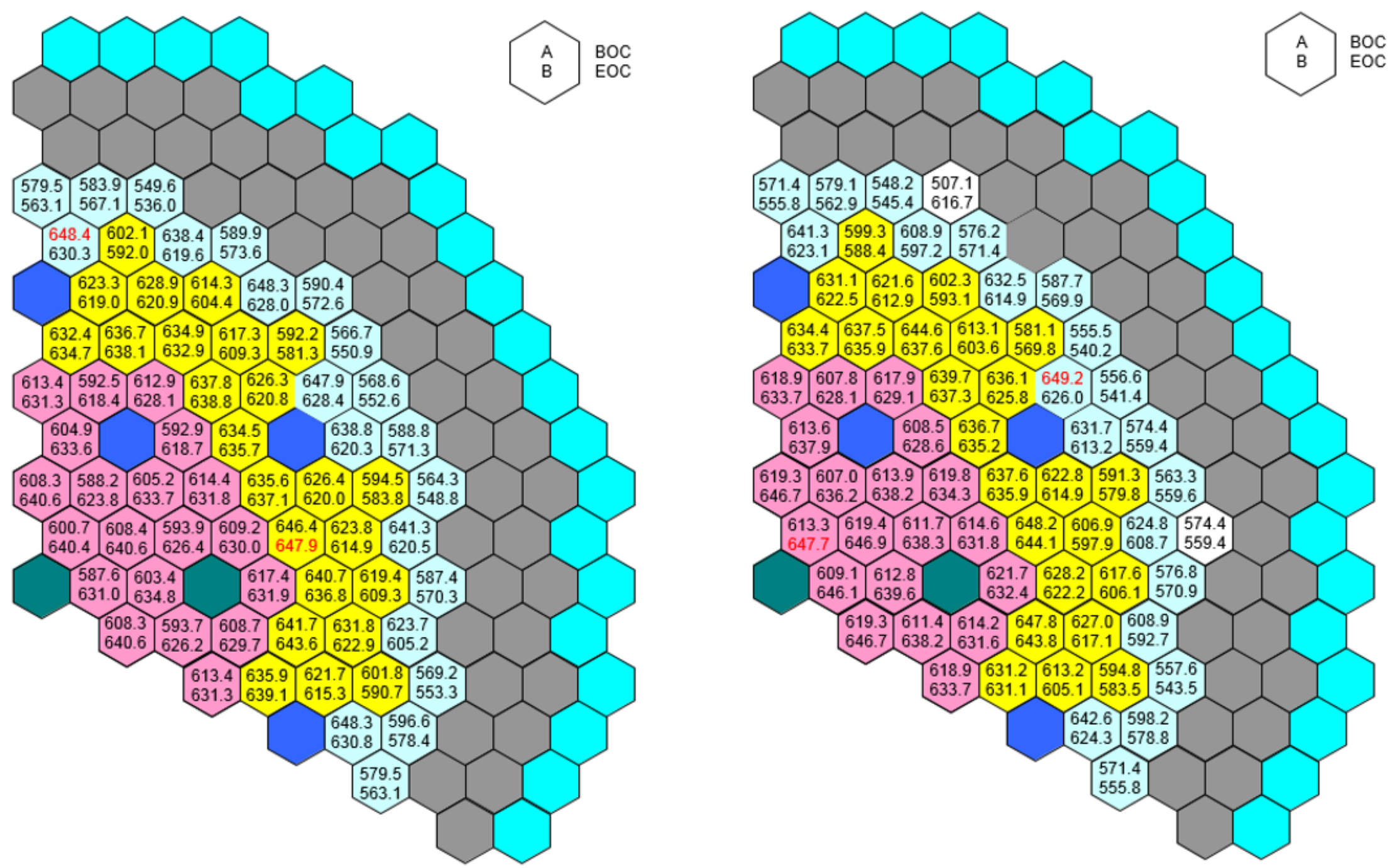

Fig. 11. Maximum 2-sigma cladding inner wall temperatures $\left({ }^{\circ} \mathrm{C}\right)$ of first-stage FR core without (left) and with target assemblies (right). 

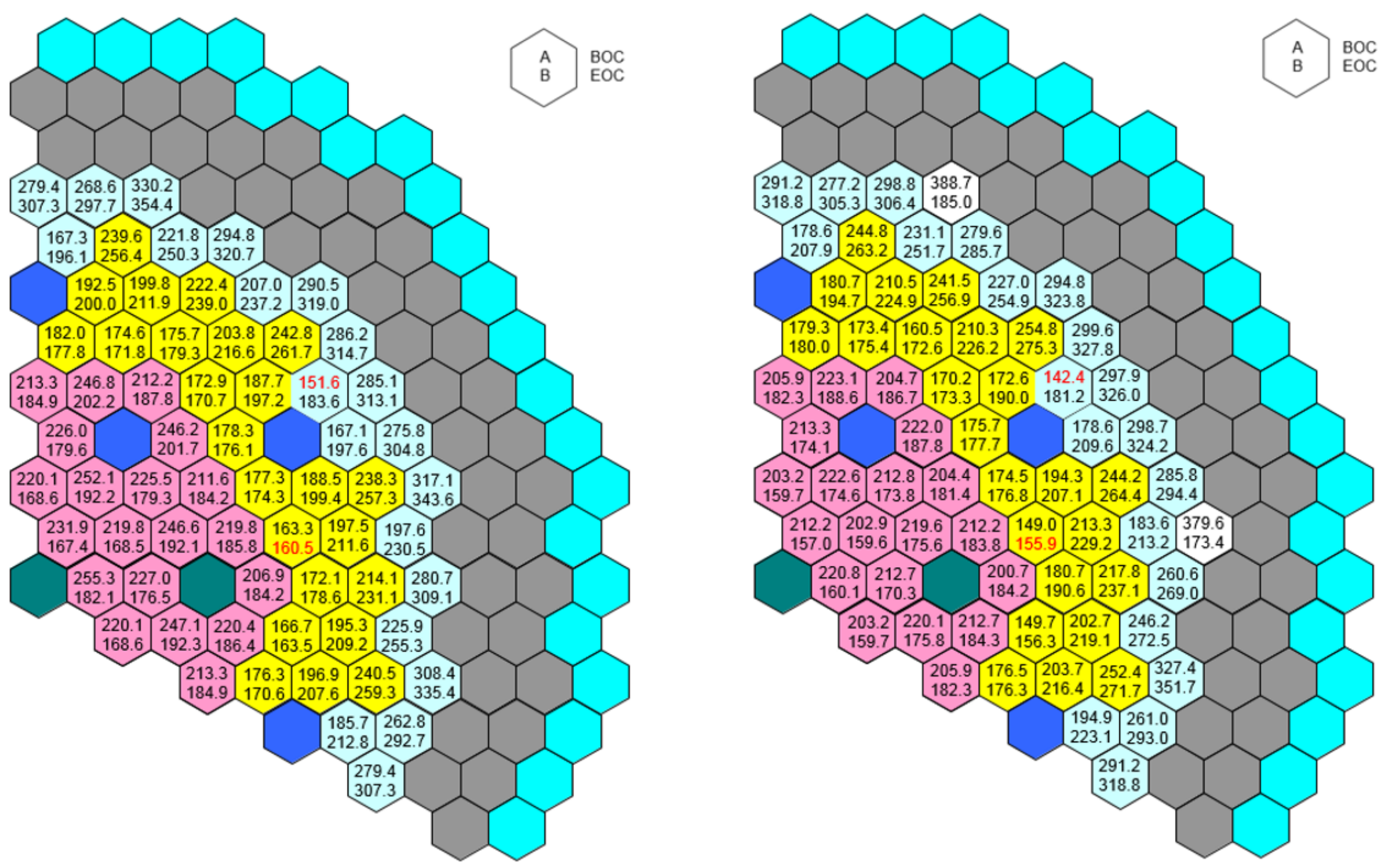

Fig. 12. Minimum 2-sigma margins to fuel melt $\left({ }^{\circ} \mathrm{C}\right)$ of first-stage FR core without (left) and with target assemblies (right). 

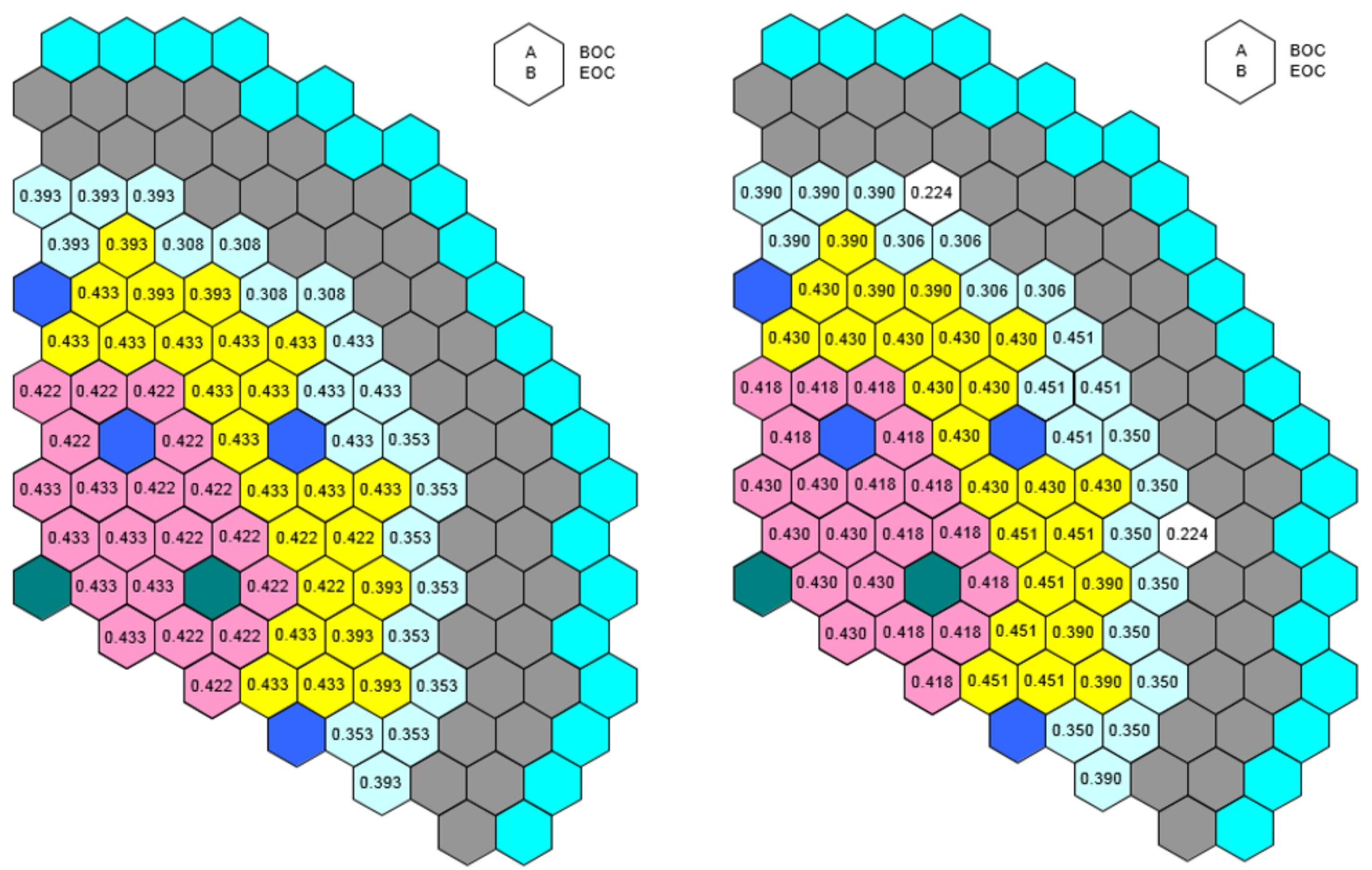

Fig. 13. Average pin bundle pressure drop (MPa) of first-stage FR core without (left) and with target assemblies (right). 